WORKING PAPER $\cdot$ NO. 2020-110

\title{
Information versus Investment
}

Stephen J. Terry, Toni M. Whited, and Anastasia A. Zakolyukina JULY 2020

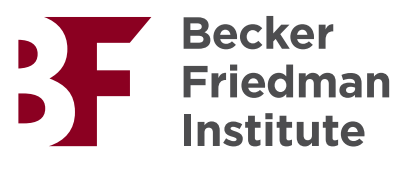




\title{
Information versus Investment
}

\author{
Stephen J. Terry Toni M. Whited Anastasia A. Zakolyukina*
}

July 2020

\begin{abstract}
The accuracy of firm information disclosures and the efficiency of long-term investment both play crucial roles in the economy and capital markets. We estimate a dynamic model that captures a trade-off between these two goals that arises when managers confront realistic incentives to misreport financial statements and distort their real investment choices. Managers in our model distort reported profits by $6.7 \%$ of sales on average. Counterfactual analysis reveals that while eliminating this misreporting through disclosure regulation is possible, it incentivizes managers to distort real investment, which results in a $1 \%$ drop in average firm value, reflecting a quantitatively meaningfully tradeoff.
\end{abstract}

* Terry is at Boston University. Whited is at the University of Michigan and the NBER. Zakolyukina is at the University of Chicago, Booth School of Business. A previous version of this paper circulated as "Information Distortion, R\&D, and Growth." We thank Clark Hyde and Hossein Pourreza for outstanding research support. We would also like to thank our discussants Johan Hombert and Massimiliano Croce, as well as seminar participants at the 2017 Stanford Theory and Inference in Capital Market Research Conference, the 2018 SED meetings, Harvard Business School, University of Maryland, University of Minnesota, Stockholm School of Economics, Bocconi University, Wirtschaftsuniversität Wien, Boston College, Boston University, Imperial College London, the London School of Economics, Erasmus University Rotterdam, the 2018 Banque de France Investment Conference, and the 2018 Tepper-LAEF Macro-Finance Conference for helpful comments. This work would have been impossible without the Extreme Science and Engineering Discovery Environment (XSEDE), which is supported by National Science Foundation grant number ACI-1053575. This research was funded in part by the Fama-Miller Center for Research in Finance at the University of Chicago Booth School of Business. Zakolyukina acknowledges financial support from the IBM Corporation Faculty Research Fund and the University of Chicago Booth School of Business, and research support from the University of Chicago Research Computing Center. 


\section{Introduction}

Shareholders rely on firm managers to carry out two distinct tasks: making long-term investment choices and disclosing information about firm performance. Both tasks matter. Firm investment ensures the long-term growth of the firm, while accurate disclosure of financial information allows for the efficient pricing of assets, which is essential for the health and transparency of capital markets overall. Unfortunately, in an incomplete contracting environment, managers' incentives need not be set to perform these two tasks optimally, so it is possible to observe a trade-off between the accurate disclosure of information and the efficiency of investment choices. Our aim is to quantify the real effects of frictions that induce firms to substitute between making efficient investment choices and revealing accurate information. As such, we examine whether the trade-off between investment efficiency and information quality is empirically important.

This question is difficult because information frictions are notoriously hard to measure, as we almost never observe the information that has been concealed, only the ongoing equilibrium with information barriers. To overcome this hurdle, we turn to the arena of earnings misreporting, which is a natural laboratory to examine a question involving information. Data on earnings announcements, realizations, and, critically, restatements are widely available. Moreover, while instances of fraudulent disclosure are infrequent, they exist, so we can observe a snapshot of investment decisions surrounding deliberate information manipulation. Of course, not all fraudulent disclosure is detected, and not all earnings restatements reveal fraud, with the result that quantifying the economic magnitude of the relevant information frictions requires imposing some structure on the data.

Therefore, we use these data to estimate a dynamic model of earnings reporting and real intangible investment, where we focus on intangible instead of fixed investment because accounting rules imply expenditures on intangibles have a much larger impact on earnings than on fixed investment expenditures. The basic idea of the model is simple. Managers 
facing short-term incentives to meet earnings targets can misreport their financial statements, distort their investment choices, or take both actions at once. Thus, if disclosure regulation causes the cost of one tool for manipulation to change, then in equilibrium, use of the other tool will be affected. To reflect this notion, in the model, managers have incentives to manipulate both intangible investment and earnings information, but they also face costs if they are caught manipulating.

The model matches a wide array of data moments related to both real investment outcomes and accounting restatements. Moreover, in the estimated model, managers choose reporting bias equal to around $6.7 \%$ of sales, conditional upon restatement, which is identical to the mean bias in the data. When we counterfactually make information manipulation prohibitively costly, managers optimally manipulate earnings more via adjustments to intangible investment. On average, firm value drops by just under $1 \%$, a nontrivial real cost.

The intuition behind these results requires a more complete description of the model, which features conflicting managerial incentives. On the one hand, managers have longterm incentives that are aligned with shareholder incentives and that are delivered by stock compensation. This part of managers' compensation package implies that they benefit when they make efficient investment choices and are hurt when they do not. On the other hand, incentive alignment between managers and shareholders is incomplete, as pressure to beat last period's earnings gives managers short-term incentives to manipulate information either by lying about earnings or by cutting investment expenditures. However, incentives to manipulate earnings are tempered because the model contains a notion of disclosure regulation, so the manager can with some probability get caught and face punishment.

With this incentive structure in place, managers then choose both long-term investment and short-term earnings manipulation to maximize their utility over an infinite horizon. They face a stochastic, decreasing returns production function that transforms intangible investment into sales, with the stochastic portion of this technology exhibiting persistence. They also face an exogenous, privately observed, transitory shock to earnings, which is 
non-fundamental in the sense that it has no effect on actual cash flows, while at the same time affecting reported earnings. Because we assume that investors use an information set that is more restricted than the manager's, investors cannot distinguish true from reported earnings and thus compensate the manager based on the reported earnings. Therefore, managers misreport earnings and also opportunistically either cut or overinvest in intangible capital at suboptimal times. The result is less accurate information provision to the public and intertemporal capital misallocation that produces an efficiency loss in real terms.

In the face of the incentives described above, a manager's choices deviate meaningfully from a value-maximizing benchmark. In particular, managers facing negative transitory shocks to earnings often choose lower levels of intangible investment in order to boost profits and deliver earnings growth. In contrast, managers facing high or positive transitory shocks usually boost their investment, thus smoothing earnings today and providing a more feasible target for tomorrow. The result is high sensitivity of investment to a transitory, non-fundamental shock that a forward-looking, value-maximizing firm would ignore entirely. Moreover, because managers can manipulate information both by misreporting and by investing suboptimally, investment policies in the model depend crucially upon disclosure regulation, which governs the manager's flexibility in biasing or misreporting information.

Our quantitative results would have been hard to obtain in a reduced form setting. Although managers can be caught misstating earnings, and although these episodes result in earnings restatements, manipulation or biases in reported earnings likely go unobserved most of the time. Moreover, the mechanisms whereby earnings manipulation spills over into real outcomes are also unobservable. Questions that are couched in terms of unobservables are prime candidates for structural estimation. For example, Zakolyukina (2018) also takes a structural approach to the estimation of the likelihood of misreporting. We build upon this work by examining not only the probability of manipulation, but also the spillover onto real firm decisions.

The general notion that there is a trade-off between information and investment is grounded 
in the survey evidence in Graham, Harvey, and Rajgopal (2005) that managers rely on both misreporting and investment distortions to manipulate earnings, with many expressing a willingness to cut intangible investment such as R\&D and advertising expenditures in order to hit an earnings target. In addition, even a cursory pass at the data provides evidence consistent with the survey's suggestions. Figure 1 plots the dynamics of intangible investment and earnings reporting bias around periods in which firms are publicly forced to revise their earnings downward, based on a sample of data that we discuss further below. Investment is around $2.5 \%$ lower in periods in which firms misreport their earnings, while earnings are biased upward at the same time. The concurrence of a dip in investment with a misreporting event is consistent with the idea that firms do indeed rely jointly on both investment and reporting tools for manipulation. The natural implication is that reduced flexibility in misreporting can result in managers' reliance on value destroying investment distortions, which we term real manipulation.

This trade-off matters because it imposes an equilibrium constraint on policy. For example, disclosure regulation, such as the Sarbanes-Oxley Act (SOX), has been criticized for forcing firms to substitute real earnings manipulation for manipulation based on the misreporting of accounting accruals (Cohen, Dey, and Lys 2008). More generally, because compensation packages with short-term incentives prompt managers to manipulate, and because these packages are pervasive (Edmans, Gabaix, and Jenter 2017), increasing information accuracy can lower real efficiency. Thus, quantifying the extent of this substitution is clearly of interest to policymakers and corporate boards.

Our project links to two distinct literatures. The first is the accounting literature that examines earnings management, as managers in our model engage in two types of management: accruals manipulation, which occurs through earnings misreporting, and real manipulation, which occurs through opportunistic changes to long-term investment. As such, this paper contributes to the empirical literatures on both accrual-based and real earnings management.

Empirical patterns consistent with accruals and real manipulation have been documented 
in reduced-form studies in accounting for decades. This literature traditionally measures both accrual-based and real earnings management using residuals from linear regressions. For example, accrual-based earnings management is measured via discretionary accruals models, which are regressions of total accruals on variables correlated with theoretical normal accruals (e.g., Jones 1991; Dechow, Sloan, and Sweeney 1995; Kothari, Leone, and Wasley 2005). Similarly, discretionary R\&D expenditures are residuals of regressions with R\&D as a dependent variable (e.g., Roychowdhury 2006; Cohen et al. 2008; Zang 2011). Using these measures, the literature has documented substitution between these regression-based measures of accrual-based and real earnings management (e.g., Cohen et al. 2008; Cohen and Zarowin 2010; Zang 2011).

We advance this literature by substituting an economic model for statistical models of manipulation and R\&D. The advantage of this approach is twofold. First, we can quantify the slope of the substitution between real and accruals manipulation. This step is both a quantitative and qualitative advance beyond the reduced-form evidence that predates ours, as the notion of the slope of a trade-off is difficult to formulate in a regression framework. Moreover, we address the call in Leuz and Wysocki (2016) for more research on the real effects of disclosure regulation and its aggregate impact on the economy. ${ }^{1}$

Second, we contribute to the large literature in finance and macroeconomics that studies distortions to real investment decisions. Here, our contribution is a demonstration that distortions caused by earnings pressures and information manipulation constitute a distinct and quantitatively important friction alongside long-studied forces such as financial frictions, adjustment costs, or agency frictions, as in Cooper and Haltiwanger (2006), Hennessy and Whited (2007), and Nikolov and Whited (2014).

Our model builds on several features of models in this literature. For example, firms in the model are subject to exogenous shocks to their productivity or profitability as in Hopenhayn

\footnotetext{
${ }^{1}$ As we model explicit incentives for manipulation, our paper also touches on the theoretical and empirical literature on moral hazard problems that can arise from performance manipulation. See, for example, Lambert (2001), Margiotta and Miller (2000), Armstrong, Jagolinzer, and Larcker (2010), Gayle and Miller (2015), Li (2016), Gayle, Li, and Miller (2016), and Glover and Levine (2017).
} 
(1992). Simultaneously, managers choose intangible investment that leads to innovation and endogenous growth from new ideas. At its core, the model features growth at the micro level that shares the same source - innovation - as models of macro-level endogenous growth (Romer 1990; Aghion and Howitt 1992). Because idiosyncratic shocks differentiate firms and drive their innovation decisions, the firm-level environment or heterogeneity is richer than in many baseline models of endogenous growth, although lumpy innovation arrivals and entry/exit dynamics are absent.

Two papers are particularly closely related to ours. The first is Terry (2015), which, like our work, examines the effects of information manipulation on R\&D. However, our work is distinct in several ways. While Terry (2015) uses a general equilibrium framework to analyze economywide impacts of short-term incentives, we use a more flexible partial equilibrium framework that allows us to make richer firm value statements. More importantly, this flexibility also allows us to examine cross-sectional heterogeneity in the effects of manipulation, as well as the large structural breaks in information disclosure rules stemming from the Sarbanes-Oxley Act (SOX). Interestingly, with regard to SOX, by estimating our model both pre- and postSOX, we find that the small change in the number of detected incidents of manipulation are the product of both an increased ex ante probability of detection and perceived cost of detection. Finally, because of the flexibility in our model, we also employ a richer misreporting environment, allowing us to endogenously target micro data on earnings restatements to identify the model parameters related to manipulation. In contrast, the misreporting structure of Terry (2015), which focuses on macroeconomic effects instead of microeconomic policy implications, is more stylized in nature.

The second closely related paper is Benmelech, Kandel, and Veronesi (2010), which explores how stock-based compensation induces mangers to conceal information and choose suboptimal investment policies. While their model shares several important trade-offs with ours, their analysis is theoretical. We extend this line of research by attempting to quantify the empirical relevance of the frictions that force important interactions between investment 
efficiency and information disclosure.

The remainder of the paper is organized as follows. Section 2 develops our model and analyzes optimal policies. Section 3 describes our data and provides summary statistics. Section 4 outlines our estimation strategy and presents our results. Section 5 describes our counterfactuals. Section 6 concludes.

\section{Model}

Time is discrete and the horizon is infinite. There is a unit mass of infinitely lived firms, each of which is run by a manager who receives both equity compensation and faces short-term pressure to sustain last period's earnings. He chooses intangible investment, as well as potential earnings misreporting to maximize his own utility.

\subsection{Firms and Fundamentals}

The firm's revenue net of flexible inputs, $Y$, is the product of endogenous quality, $Q$, and exogenous productivity, $\nu_{y}$, which follows an $A R(1)$ process in logs:

$$
\log \nu_{y}^{\prime}=\rho_{y} \log \nu_{y}+\eta_{y}^{\prime}, \quad \eta_{y}^{\prime} \sim N\left(0, \sigma_{y}^{2}\right)
$$

Here, a prime indicates a variable in the subsequent period, and $\left|\rho_{y}\right|<1$. Consistent with much of the endogenous growth literature (Romer 1990), the production function $Y=\nu_{y} Q$ exhibits increasing returns in the sum of endogenous quality, $Q$, and exogenous quality, $\nu_{y}$. The manager can choose expenditures in intangible capital or $\mathrm{R} \& \mathrm{D}$, denoted as $W$, which drives growth in endogenous productivity $Q$ according to:

$$
Q^{\prime}-Q=\Delta Q^{\prime}=\xi W^{\gamma} Q^{1-\gamma}, \quad 0<\gamma<1
$$


The parameter $\xi$ is a multiplicative productivity shifting parameter. For simplicity, we assume that $Q$ does not depreciate and there are no adjustment costs for intangible investment. These assumptions are innocuous, as none of our eventual model predictions depend on the variable $Q$.

Finally, we also assume there is no physical capital. While this assumption helps us maintain model simplicity and tractability, it is also innocuous. Investment in property, plant, and equipment is not immediately expensed, this type of investment only has an impact on earnings when it is depreciated, so the ex ante likelihood of a large impact on earnings management is small.

This investment technology exhibits decreasing returns, given by $\gamma$, and it implies that the growth rate in endogenous productivity is identically given by:

$$
g \equiv \frac{\Delta Q^{\prime}}{Q}=\xi\left(\frac{W}{Q}\right)^{\gamma}
$$

Distributions to shareholders, $D$, are given by output minus R\&D:

$$
D \equiv Y-p_{w} W
$$

in which $p_{w}$ is the price of $\mathrm{R} \& \mathrm{D}$ relative to output. Because we have no depreciated capital expenditures in the model, from an accounting perspective, $Y-p_{w} W$ can be thought of as intrinsic earnings that ultimately convert to shareholder cash flows.

\subsection{Reporting and Manipulation}

In each period, the firm must report its earnings, $\Pi$, to investors. We allow for observed earnings to deviate from intrinsic earnings, $Y-p_{w} W$, in two ways. First, we specify an accounting shock, $\nu_{\pi}$ that drives non-fundamental exogenous variation in earnings $\Pi$, with

$$
\nu_{\pi} \sim N\left(0, \sigma_{\pi}^{2}\right)
$$


This shock has no actual cash flow consequences and simply reflects deficiencies in accounting standards related to accurate estimation of intrinsic cash flows. Below, we refer to the shock, $\nu_{\pi}$, as a non-fundamental shock or profit shock.

Second, the manager can manipulate earnings by introducing bias into the book value of the firm because earnings represent the first difference of book value. As such, the manager enters the current period with an inherited bias in book value given by $B_{-1}$. He then chooses a new level of bias, $B$, to obtain a net distortion in reported earnings equal to $B-B_{-1}$. These two extra components of earnings imply that

$$
\Pi \equiv Y-p_{w} W+\nu_{\pi} Q+B-B_{-1}
$$

While the investor can observe $\Pi, Y$, and $p_{w} W$, the investor cannot observe the individual components of the term $\nu_{\pi} Q+B-B_{-1}$. In addition, this specification allows for the mechanical partial reversal of accruals-based manipulation because the manager can always compensate for any reversal of bad accruals by manipulating even more with an appropriate choice of $B$.

If the new choice of bias, $B$, is nonzero, then the manager faces a constant probability, $\lambda$, of discovery. ${ }^{2}$ This model feature realistically implies that a manager can go for some time without getting caught. In addition, he can also reverse the manipulation in those periods in which he does not get caught and thus remain forever undetected for that specific episode of manipulation. If he is discovered, he must pay a private cost of

$$
M C(B, Q)=\left[\kappa_{f}+\kappa_{q}\left(\frac{B}{Q}\right)^{2}\right] Q, \quad \kappa_{f}, \kappa_{q} \geq 0
$$

In principle, such costs could arise either outside the firm from investor pressures or litigation risk. Alternatively, they could arise inside the firm as a part of a sophisticated manager

\footnotetext{
${ }^{2}$ While intuition would suggest that the probability of detection ought to depend on the size of the bias, the rarity of restatements does not allow us to identify the relation between bias size and detection probability, so we opt for the simpler specification of a constant probability.
} 
compensation contract. In addition, such costs could represent real disruptions and resource losses for the firm itself (e.g., litigation risk) or purely non-pecuniary internal costs for the manager (e.g., career or reputational concerns). In our counterfactuals below, we want to isolate the effects of these costs on managerial actions, and we want to avoid a purely mechanical impact of the costs themselves on the implied changes in firm value. Therefore, we conservatively assume that all of the smoothing and misreporting incentives reflected in (6) are purely non-pecuniary and internal to the manager. Finally, we assume that upon discovery and after payment of the private cost, $M C(B, Q)$, bias is unwound, that is, $B$ is reset to zero.

\subsection{Managers' Incentives}

Managers are risk neutral, and their compensation contracts have two components. The first is a fixed fraction, $\theta_{d}>0$, of the outstanding equity of the firm, so the manager receives the same fraction, $\theta_{d}$, of the distributions to shareholders. The second component is the short-term pressure to sustain last period's earnings, $\theta_{f} \geq 0$. We assume that each period the manager is incentivized to report earnings at least as high as last period's earnings, denoted as $\Pi_{-1}$. Thus, each period the manager receives a cash flow of $D_{M}$, which is given by:

$$
D_{M} \equiv \theta_{d} D+\theta_{f} \mathbf{1}\left\{\Pi \geq \Pi_{-1}\right\}
$$

This payoff omits fixed compensation because the manager's risk neutrality renders such compensation irrelevant for the manager's choice of policies. The two components of compensation that we model have important implications for the manager's actions. The stock component aligns the managers' incentives with those of long-term shareholders, while the short-term earnings growth component gives the manager an incentive to report current period's earnings at least as high as last period's earnings. While we model the incentives to improve over last period's earnings for simplicity, any compensation scheme that has jumps in 
the measures of firm performance, such as the stock price or earnings, would provide similar incentives. Performance-based equity grants, options-based compensation, and bonus plans serve as examples.

We motivate this compensation scheme in large part by the survey of CEO compensation by Frydman and Jenter (2010), which documents that most CEO compensation packages contain salary, bonuses, payouts from long-term incentives plans, and restricted option and stock grants. Performance-based equity grants have been increasing since the mid-1990s (Bettis, Bizjak, Coles, and Kalpathy 2010) and have outpaced options as the most popular form of equity compensation after 2004 (Edmans et al. 2017). Similar to bonus plans, these performance-based equity grants often have a discrete jump at the lower performance threshold and an "incentive zone" (Bettis, Bizjak, Coles, and Kalpathy 2018). These plans are often very complex and, for instance for performance shares, can have linear or non-linear mapping from performance to the number of securities granted in the incentive zone. They are also often based on many performance metrics (e.g., Gerakos, Ittner, and Larcker 2007; Bettis et al. 2010, 2018). Accounting-based performance metrics are used more frequently than stock-based metrics, with earnings-based metrics being the most common accounting measure (Edmans et al. 2017). We focus on the discrete jump in compensation and abstract away from the performance-payoff mapping in the incentive zone. Besides the complexity of performance-based equity compensation contracts, another reason to consider only discrete jumps is the large literature on "meeting or beating" earnings targets. This literature shows that reported earnings tend to exceed three thresholds: avoiding losses, sustaining recent earnings, and meeting analysts' expectations (e.g., Burgstahler and Dichev 1997; DeGeorge, Patel, and Zeckhauser 1999). For these reasons, we focus on last period's earnings as a performance threshold.

As in Nikolov and Whited (2014) and Glover and Levine (2017), we remain silent on the optimality of these incentives. Instead, we seek to quantify empirically the trade-off between information and investment in the face of incentives that are widely observed but that do not 
necessarily induce behavior that maximizes shareholder value. This strategy is sensible given the evidence in Dittmann and Maug (2007) that standard principal-agent models cannot rationalize observed executive compensation contracts. Alternatively, another reasonable view of this compensation policy is that it is a reduced-form description of a contracting outcome that allows for equilibrium self-interested behavior on the part of the agent, as in Zhu (2013). One final alternative interpretation of our contracting specification is that the contracting environment is incomplete and that the contract we specify is optimal, given an agency issue that is outside the model and that we do not observe. The incompleteness of the contracting environment would then imply that the misbehavior that we model cannot be contained via contracts.

\subsection{Managers' Dynamic Optimization Problem}

We now describe the manager's dynamic optimization problem. He faces a state vector at any time of $\left(\nu_{y}, \nu_{\pi}, \Pi_{-1}, B_{-1}, Q\right)$, and he discounts cash flows at a rate $r$. He optimally chooses R\&D, $W$, and new gross bias, $B$. Given that the manager wants to maximize the expected discounted value of his compensation, the manager's private value function is given by $V_{M}$, as follows:

$V_{M}\left(\nu_{y}, \nu_{\pi}, \Pi_{-1}, B_{-1}, Q\right)=\max _{W, B}\left\{\begin{array}{r}\mathbb{I}(B=0)\left(D_{M}+\frac{1}{1+r} \mathbb{E} V_{M}\left(\nu_{y}^{\prime}, \nu_{\pi}^{\prime}, \Pi, 0, Q^{\prime}\right)\right) \\ + \\ \mathbb{I}(B \neq 0)(1-\lambda)\left(D_{M}+\frac{1}{1+r} \mathbb{E} V_{M}\left(\nu_{y}^{\prime}, \nu_{\pi}^{\prime}, \Pi, B, Q^{\prime}\right)\right) \\ + \\ \mathbb{I}(B \neq 0) \lambda\left(\left.D_{M}\right|_{B=0}-M C(B, Q)+\frac{1}{1+r} \mathbb{E} V_{M}\left(\nu_{y}^{\prime}, \nu_{\pi}^{\prime},\left.\Pi\right|_{B=0}, 0, Q^{\prime}\right)\right),\end{array}\right\}$

subject to the constraints and definitions given in (1)-(7). The first line in curly brackets in

(8) is the value to the manager if he chooses not to engage in book-value manipulation. The 
second line represents the case in which he chooses to manipulate but does not get caught. The third line represents the case in which he does get caught.

While (8) gives lifetime managerial utility, it does not represent the fundamental value of the firm, which we denote as $V_{F}$, and which is simply the expected present value of distributions to shareholders. On the basis of the manager's privately optimal policies $B^{*}$ and $W^{*}$, the fundamental value of the firm $V_{F}$ is thus given by

$$
V_{F}\left(\nu_{y}, \nu_{\pi}, \Pi_{-1}, B_{-1}, Q\right)=\left\{\begin{array}{r}
\mathbb{I}\left(B^{*}=0\right)\left(D^{*}+\frac{1}{1+r} \mathbb{E} V_{F}\left(\nu_{y}^{\prime}, \nu_{\pi}^{\prime}, \Pi, 0, Q^{\prime}\right)\right) \\
\left.+\quad \frac{1}{1+r} \mathbb{E} V_{F}\left(\nu_{y}^{\prime}, \nu_{\pi}^{\prime}, \Pi, B^{*}, Q^{\prime}\right)\right) \\
+ \\
\mathbb{I}\left(B^{*} \neq 0\right)(1-\lambda)\left(D^{*}+\frac{1}{1+r} \mathbb{E} V_{F}\left(\nu_{y}^{\prime}, \nu_{\pi}^{\prime},\left.\Pi\right|_{B=0}, 0, Q^{\prime}\right)\right.
\end{array}\right\},
$$

in which $D^{*}$ is given by $(3)$, evaluated at the policies $B^{*}$ and $W^{*}$. We note that in the absence of the incentives to sustain last period's earnings (the case $\theta_{f}=0$ ) the manager has no incentive to manipulate, so managerial utility, (8), equals fundamental firm value (9).

Next, to reduce the state space of the model, we normalize output, R\&D, and distributions by endogenous productivity, $Q$, as follows:

$$
y \equiv \frac{Y}{Q}=\nu_{y}, \quad d \equiv \frac{D}{Q}=y-p_{w} w, \quad w \equiv \frac{W}{Q} .
$$

Earnings also naturally scale linearly with $Q$, so scaled earnings are given by:

$$
\pi \equiv \frac{\Pi}{Q}=y-p_{w} w+\nu_{\pi}+b-b_{-1}, \quad b \equiv \frac{B}{Q}, \quad b_{-1} \equiv \frac{B_{-1}}{Q}
$$

Similarly, normalized by endogenous productivity, $Q$, manager incentives are given by

$$
d_{m} \equiv \frac{D_{M}}{Q}=\theta_{d} d+\theta_{f} \mathbf{1}\left\{\pi \geq \pi_{-1}\right\}
$$


The manager's value function (8) is homogeneous in $Q$, so we can write

$$
V_{M}\left(\nu_{y}, \nu_{\pi}, \Pi_{-1}, B_{-1}, Q\right)=Q v_{m}\left(\nu_{y}, \nu_{\pi}, \pi_{-1}, b_{-1}\right)
$$

where the normalized manager value function is given by

$$
v_{m}\left(\nu_{y}, \nu_{\pi}, \pi_{-1}, b_{-1}\right)=\max _{w, b}\left\{\begin{array}{r}
\mathbb{I}(b=0)\left(d_{m}+\frac{1+g(w)}{1+r} \mathbb{E} v_{m}\left(\nu_{y}^{\prime}, \nu_{\pi}^{\prime}, \frac{\pi}{1+g(w)}, 0\right)\right) \\
+ \\
\mathbb{I}(b \neq 0)(1-\lambda)\left(d_{m}+\frac{1+g(w)}{1+r} \mathbb{E} v_{m}\left(\nu_{y}^{\prime}, \nu_{\pi}^{\prime}, \frac{\pi}{1+g(w)}, \frac{b}{1+g(w)}\right)\right) \\
+ \\
\mathbb{I}(b \neq 0) \lambda\left(\left.d_{m}\right|_{b=0}-m c(b)+\frac{1+g(w)}{1+r} \mathbb{E} v_{m}\left(\nu_{y}^{\prime}, \nu_{\pi}^{\prime},\left.\frac{\pi}{1+g(w)}\right|_{b=0}, 0\right)\right.
\end{array}\right\}
$$

subject to the following constraints and processes:

$$
\begin{aligned}
y & =\nu_{y}, \quad \log \nu_{y}=\rho_{y} \log \nu_{y,-1}+\eta_{y}, \quad \eta_{y} \sim N\left(0, \sigma_{y}^{2}\right) \\
d & =y-p_{w} w \\
\nu_{\pi} & \sim N\left(0, \sigma_{\pi}^{2}\right) \\
\pi & =y-p_{w} w+\nu_{\pi}+b-b_{-1} \\
d_{m} & =\theta_{d} d+\theta_{f} \mathbf{1}\left\{\pi \geq \pi_{-1}\right\} \\
m c(b) & =M C(b, 1) \\
g(w) & =\xi w^{\gamma} .
\end{aligned}
$$


An equivalent scaled concept for fundamental firm value, $v_{f} \equiv \frac{V_{F}}{Q}$, exists and is given by:

$$
v_{f}\left(\nu_{y}, \nu_{\pi}, \pi_{-1}, b_{-1}\right)=\left\{\begin{array}{c}
\mathbb{I}(b=0)\left(d+\frac{1+g(w)}{1+r} \mathbb{E} v_{f}\left(\nu_{y}^{\prime}, \nu_{\pi}^{\prime}, \frac{\pi}{1+g(w)}, 0\right)\right) \\
+\quad\left(d+\frac{1+g(w)}{1+r} \mathbb{E} v_{f}\left(\nu_{y}^{\prime}, \nu_{\pi}^{\prime}, \frac{\pi}{1+g(w)}, \frac{b}{1+g(w)}\right)\right) \\
\mathbb{I}(b \neq 0)(1-\lambda)\left(d+\frac{1+g(w)}{1+r} \mathbb{E} v_{f}\left(\nu_{y}^{\prime}, \nu_{\pi}^{\prime},\left.\frac{\pi}{1+g(w)}\right|_{b=0}, 0\right)\right) \\
\mathbb{I}(b \neq 0) \lambda\left(d+\frac{1}{1+r}\right)
\end{array}\right\} .
$$

Here, the fundamental firm value function is evaluated at the optimal policies, $(b, w)$, derived from the manager dynamic optimization in (10), and the transitions and constraints are identical to those in the definition of $v_{m}$.

Scaling implies that all of our lower case variables are measured in terms of dollars per quality unit. Because quality units are unobservable, our model has natural empirical predictions for the growth rates and ratios of observable variables, but not for the levels.

\subsection{Model Solution Algorithm}

To solve the model, which does not have a closed-form solution, we rely on standard numerical dynamic programming techniques applied to the stationary (scaled) recursive formulation in (10). Besides the usual challenge of solving a model with a high number of endogenous policies and state variables, however, there is an additional complication introduced by the non-stationarity of the underlying problem in this firm-level growth model. The solution is sensitive to the discounting implied by the quality growth rate, $g(w) \equiv \xi w^{\gamma}$, which appears in both the continuation values of (10) and the endogenous state transitions. Because a firm's desired R\&D level, $w$, and hence its growth rate, $g(w)$, depend crucially upon the efficiency of $\mathrm{R} \& \mathrm{D}$, as embodied in the parameter $\xi$, the value of the parameter $\xi$ matters a great deal for the stability and nature of the implied numerical solution of the model. To ensure a reasonable value for growth and a stable solution, we iterate on the value of R\&D efficiency $\xi$ 
until one of the easily observed growth rates in the model matches its empirical counterpart.

We implement the procedure as follows. First, given a vector of parameter values excluding $\xi$, we compute the average sales growth rate from the data, $\hat{g}_{y}^{\text {data }}$. Next, we choose the value of $\xi$ in the model to satisfy the following equation:

$$
g_{y}^{s i m}(\xi)=\hat{g}_{y}^{d a t a}
$$

in which $g_{y}^{\operatorname{sim}}(\xi)$ is the average sales growth rate in the model. We solve (12) via bisection, re-solving the model at different candidate values of $\xi$ until (12) holds to a preset tolerance. This algorithm for determining the value of $\xi$, whose value depends both upon the empirical sales growth rate as well as value of the other parameters in the model, works well in practice.

\subsection{Revenue Recognition}

The model contains one further parameter that does not enter into the managerial optimization problem but that does enter into the simulation of data from the model and is important for matching simulated with actual data moments. This parameter reflects accrual accounting, which is an important feature of earnings measurement and which is designed to provide a better indication of company's performance or economic earnings than operating cash flows (FASB 1978)..$^{3}$

Accrual accounting induces a wedge between the measurements of earnings and operating cash flows, so accounting earnings do not generally correspond to cash inflows and outflows for the period. Moreover, because accruals are managers' forecasts of future cash flows, these forecasts must reconcile with realized cash flows in the future (e.g., Allen, Larson, and Sloan 2013; Nikolaev 2016). This reconciliation property implies that we can view operating cash flows as a reshuffling of accounting earnings across adjacent periods. As such, we allow for a

\footnotetext{
${ }^{3}$ According to Statement of Financial Accounting Concepts No. 1, "Information about enterprise earnings based on accrual accounting generally provides a better indication of an enterprise's present and continuing ability to generate favorable cash flows than information limited to the financial effects of cash receipts and payments."
} 
random portion of accounting earnings to be realized as cash flows in the periods immediately before or immediately after the current period. Although we allow for reshuffling in only one adjacent period, this idea is similar to the mechanism underlying the accrual quality measure in Dechow and Dichev (2002), who represent accounting earnings as the sum of past, present, and future cash flows that are recognized in the current period earnings, with an allowance for estimation errors.

To implement this principle, we first define a parameter $\hat{p}_{s} \in(0,1)$, which represents the probability of intertemporal cash flow reshuffling. Next, we draw a set of uniform shocks, $\zeta_{i t}^{s}, \quad \forall i, t$, where $i$ indexes firms and $t$ indexes time. We then initialize observed cash flows

at time 1 , which we denote $\tilde{d}_{i, 1}$, equal to the actual cash flow simulated directly from the model, that is, $\tilde{d}_{i, 1} \equiv y_{i, 1}-p_{w} w_{i, 1}$. Finally, iteratively progressing from $t=2, \ldots, T-1$ for each firm $i$, we update the observed cash-flow series by the following rules:

$$
\begin{aligned}
& \text { If } \zeta_{i t}^{s}<0.5, \text { set } \quad \tilde{d}_{i t-1}=\tilde{d}_{i t-1}+2 \hat{p}_{s}\left(0.5-\zeta_{i t}^{s}\right) \text { and } \tilde{d}_{i t}=\tilde{d}_{i t}-2 \hat{p}_{s}\left(0.5-\zeta_{i t}^{s}\right) \\
& \text { If } \zeta_{i t}^{s}>0.5, \text { set } \tilde{d}_{i t+1}=\tilde{d}_{i t+1}+2 \hat{p}_{s}\left(\zeta_{i t}^{s}-0.5\right) \text { and } \tilde{d}_{i t}=\tilde{d}_{i t}-2 \hat{p}_{s}\left(\zeta_{i t}^{s}-0.5\right) \text {. }
\end{aligned}
$$

In words, this procedure randomly pushes forward some portion of today's cash flows into tomorrow and yesterday, given the random mistiming or reshuffling shock, $\zeta_{i t}^{s}$, keeping the sum of cash flows over any medium-term horizon unchanged, where the horizon is three years.

\subsection{Optimal Policies}

Each period, the manager chooses how much to invest and whether to bias her earnings report. Figure 2 plots her choices as a function of the persistent fundamental shock, $\nu_{y}$ (left column) and the transitory profit shock $\nu_{\pi}$ (right column). The top row plots the mean investment or R\&D choices of the firm as a function of each shock, and the bottom row plots the mean bias chosen by managers.

In the top left panel, we see an intuitive positive response of $R \& D$ investment to the 
fundamental shock because higher values of the persistent shock today indicate a higher average marginal product of $R \& D$. Such a pattern and mechanism would also be present in a fully value maximizing model.

However, $\theta_{f}>0$ in the estimated model implies the presence of managerial manipulation incentives, so managers also adjust R\&D investment in response to the transitory profit shock, $\nu_{\pi}$ (top right panel). This profit shock contains no information about the payoff to investment, and a value maximizing manager would ignore it. However, a low short-term transitory shock today on average causes managers with earnings growth incentives to cut intangible investment. Conversely, a high short-term profit shock creates higher profits today and a more difficult earnings benchmark tomorrow, so managers have an incentive to increase R\&D to dampen the realized increase in profits. The result is a positive relation between R\&D on $\nu_{\pi}$ seen in Figure 2.

The manager's choice of bias also responds the fundamental and profit shocks. For example, in order to boost profits above lagged levels, managers with low levels of the fundamental shock choose a level of bias higher than the level chosen by managers with high levels of the fundamental shock (bottom left panel). As seen in the bottom right panel, the relation between bias and the profit shock is also downward sloping. If the profit shock is low, the manager is unlikely to meet her target, so she chooses a high bias level. By contrast, a high profit shock means that the manager is more likely to meet her target, so she is likely to choose a low bias level.

The main message from Figure 2 is that managers choose to use both investment and bias as tools for profit manipulation, allowing for substitution between the two. Moreover, the responsiveness of investment to non-fundamental transitory shocks to profits implied by the estimated model implies substantial scope for misallocation and lost firm value. 


\section{Data}

\subsection{Sources}

The data come from three sources. The financial data are from Compustat. The data on executive compensation are from Equilar, which collects these data from annual proxy filings (DEF 14A). Equilar's coverage is more than double the coverage of Compustat ExecuComp, whose universe is the S\&P 1500, while Equilar covers virtually all public companies. The data on restatements are from Audit Analytics, where we use restatements that correct accounting errors as a measure of detected misstatements.

Data availability from the intersection of these three sources means that our sample spans seventeen years from 1999 to 2015 and includes firms incorporated in the United States and listed on the NYSE, Amex, or NASDAQ. For firms included in the sample, we require all variables used in the estimation to be non-missing. Because we need sufficient time-series variation in our data to identify some of our model parameters, we also require seven years of sales revenue data, where three years of these data must be consecutive.

We further consider two samples of firms, which correspond to two definitions of intangible investment. The first definition is SG\&A, which is a broad measure that includes expenditure on strict R\&D, as well as on organizational capital (Eisfeldt and Papanikolaou 2013). The second definition is strict R\&D. Given these definitions, the first sample excludes firms for which all SG\&A expenses are missing or zero (SG\&A sample), and the second sample excludes firms for which all $R \& D$ expenses are missing or zero ( $R \& D$ sample). These restrictions retain

firms for which the discretionary investment into SG\&A or R\&D decisions are relevant. For both samples, we further exclude firms in the financial and utilities sectors, which we define as Global Industry Classification Standard (GICS) sectors 40, 55, and 60. For the R\&D sample, we also exclude transportation (GICS sector 2030) and food and staples retailing (GICS sector 3010). Table 1 provides definitions of all of our variables. 
Next, we describe our use of the Audit Analytics data, where the main issue is the definition of intentional manipulation. Although in our model, manipulation is chosen intentionally and optimally by the manager, in the data, not all observed restatements correct intentional manipulation (Hennes, Leone, and Miller 2008; Karpoff, Koester, Lee, and Martin 2017). As such, classifying restatements as intentional incurs some unavoidable discretion, and the choice of any particular definition of an intentional restatement reflects a trade-off between the number of restatements and the likelihood that these restatements correct intentional misstatements. We therefore adopt two definitions of an intentional misstatement.

The first definition includes restatements of revenue recognition errors, where we identify revenue recognition restatements with the Audit Analtytics data. ${ }^{4}$ We focus on revenue recognition restatements because they elicit the largest negative market reaction relative to other types of errors, such as expense recognition errors (e.g., Palmrose, Richardson, and Scholz 2004; Scholz 2008). Moreover, the closely related model of intentional manipulation in Zakolyukina (2018) has more power to explain revenue recognition errors.

The second definition includes three separate groups of restatements, each of which is classified as an irregularity under a separate criterion. We create the first group following the classification scheme in Hennes et al. (2008), searching all of Audit Analytics' restatement disclosure textual narratives for the three patterns defined in this paper. The first is the presence of derivative forms of the words "fraud" or "irregularity." The second is SEC or Department of Justice formal or informal investigations. The third is discussion of independent investigations by an audit committee or a special committee. After automatic pre-screening for search terms, we read each relevant disclosure to make a final judgment about whether the particular disclosure can be classified as an irregularity.

The second group is restatements surrounded by events pointing to potential irregularities as specified in Appendix 2 in Cheffers, Usvyatsky, and Pakaluk (2014). For instance, these

\footnotetext{
${ }^{4}$ Because we want to isolate errors, as opposed to revisions, our sample excludes retrospective revisions related to the application of SEC Staff Accounting Bulletin (SAB) No. 101. Thus, our sample includes only errors in SAB 101 implementation.
} 
events include $\mathrm{CEO}$ or $\mathrm{CFO}$ dismissals resulting from internal investigations or suspected wrongdoing, auditor changes related to SEC inquiry or management unreliability, or overlap between the restated period and the violation period alleged by the Accounting and Auditing Enforcement Releases (AAERs) from Dechow, Ge, Larson, and Sloan (2011). We require these events to happen within one year before or after the restatement.

The third group is restatements that involve Rule 10b-5 allegations of fraud, both in cases brought by the SEC and in security class action lawsuits. A Rule 10b-5 allegation requires scienter (Choi and Pritchard 2016) and thus represents a category of misstatements with allegations of intentional fraud. For class action lawsuits, we require that the case not be dismissed or terminated. We also require a related AAER period to overlap with the periods restated for the SEC cases. For the security class action lawsuits, we require the class period to overlap with the periods restated. In each case, we read legal summaries to confirm that allegations involve earnings misstatements. We exclude two categories of restatements from the irregularity group - lease restatements and option backdating restatements - as both are less likely to be intentional. ${ }^{5}$

For our main specification, we combine revenue recognition and irregularity restatements, although we later examine the irregularity restatements separately. Finally, for all restatements, we require that misstatements have a nonzero net income effect over restated period. This requirement is important because in the estimation, we set the bias in book value equal to the cumulative impact of a restatement on net income. Finally, we only keep restatements that correct annual financial statements.

\subsection{Subsample construction}

Our sample period covers one significant change in disclosure regulation - the Sarbanes-Oxley Act (SOX), which constituted a major change in disclosure regulation (Coates and Srinivasan

\footnotetext{
${ }^{5}$ In the Audit Analytics taxonomy, lease restatements correspond to the categories 21 (Lease SFAS 5 legal contingency and commitment issues) and 42 (Lease leasehold and FAS 1398 only subcategory). Option backdating corresponds to categories 17 (Deferred stock-based and/or executive compensation issues) and 48 (Deferred stock-based options backdating only subcategory).
} 
2014). SOX contains three notable sections regarding financial disclosures. First, Section 302 requires CEOs and CFOs to certify financial statements and establishes CEOs and CFOs as having direct responsibility for the accuracy of financial reports and internal controls over financial reporting. Second, Section 404[a] requires management certification of internal controls over financial reporting. Third, Section 404[b] requires auditors to attest to the management's assessment of internal controls.

This legislation and concurrent events have changed the expected cost of manipulation, both in terms of detection probability and penalty. Indeed, the incidence of restatements increased dramatically right after the passage of SOX and peaked after the SOX Section 404 implementation of internal control disclosures in 2004 (Whalen, Usvyatsky, and Tanona 2016). This pattern is consistent with detection probability increasing in the post-SOX period. Accordingly, there are two distinct regimes that can affect the misstatement cost parameters: the pre-SOX period ending in August 2002 and the post-SOX period. As will be seen below, we treat these two sub-periods differently in our estimation.

\subsection{Summary statistics}

Table 2 (Panel A) provides descriptive statistics for restatements, CEO compensation, and firm characteristics for the SG\&A sample. For the combined sample of restatements, the mean (median) bias in book value is $\$ 57$ (\$6.4) million or $6.7 \%(1.1 \%)$ of sales. The corresponding bias in earnings is $\$ 15.2(\$ 1.4)$ million or, highly skewed, $172.6 \%(0.2 \%)$ of sales. For the irregularity restatements, the mean (median) bias in book value is $\$ 76.3(\$ 10.6)$ million or $7.9 \%(1.5 \%)$ of sales. The corresponding bias in earnings is $\$ 20.2(\$ 1.9)$ million or, highly skewed, $240.4 \%(0.3 \%)$ of sales. In line with the evidence in Frydman and Jenter (2010), the mean (median) CEO holds $5.2 \%(0.7 \%)$ of all outstanding stock.

Table 2 also provides descriptive statistics for the variables used in our estimations, as well as other firm characteristics. Many of these variables are growth rates, which we compute as differences relative to the absolute value of an average following Davis and Haltiwanger 
(1992) and Terry (2015). For instance, the one-year growth in $x_{t}$ is computed as:

$$
\Delta x=\left\{\begin{array}{l}
0, x_{t}=0 \text { and } x_{t-1}=0 \\
2 \frac{x_{t}-x_{t-1}}{\left|x_{t}\right|+\left|x_{t-1}\right|}, \text { otherwise. }
\end{array}\right.
$$

These growth rates have the advantage of being bounded within $[-2 ; 2]$. This restriction is important because often variables shift from zero to nonzero values, so, for example, the shift from zero to positive $R \& D$ investment results in a finite rather than a missing value.

The mean one-year growth in cash flows is $5.7 \%$, the one-year growth in earnings is $4.4 \%$, the one-year growth in SG\&A is $5.7 \%$, the one-year growth in R\&D is $3.3 \%$, and the three-year growth in sales is $19.3 \%$. Finally, the firms in our sample are identical in size to a generic Compustat sample. Mean firm assets are $\$ 2.82$ billion in our sample, while the mean assets of all firms in Compustat over the same period is $\$ 2.52$ billion. $^{6}$

\section{Estimation}

We set two parameters outside the estimation. First, we set the discount rate, $r$, to $6 \%$. This figure represents a premium over the $3.84 \%$ average rate on the ten-year Treasury bond over our sample period, and it is generally consistent with evidence that managers set discount rates higher than one would predict using a standard model (Graham and Harvey 2001). Next, we normalize the fraction of manager dividend claims, $\theta_{d}$ to one. This normalization is without loss of generality, as $\theta_{d}>0$ exchanges units with $\theta_{f}$, which is the manager's incentives to meet or beat earnings.

We also estimate two parameters separately: the innovation productivity shifter, $\xi$, and the rate of earnings conversion to cash flows, $\hat{p}_{s}$. The parameter $\xi$ shifts the innovation production function and thus maps strongly and positively into the mean sales growth rate, $\mathbb{E}_{y} \Delta_{3} y$, which we compute as the sales-weighted three-year growth rate of sales, given by

\footnotetext{
${ }^{6}$ Panel B provides the same statistics for the R\&D sample, showing similar patterns in this sample.
} 
$\mathbb{E}_{y}\left(y_{i, t-3} \Delta_{3} y_{i, t}\right) / \mathbb{E}_{y}\left(y_{i, t-3}\right)$, with $\Delta_{3} y_{i, t}=2\left(y_{i, t}-y_{i, t-3}\right) /\left(y_{i, t}+y_{i, t-3}\right)$. We use a sales-weighted growth rate because the unweighted average sales growth rate of $19.3 \%$ in Table 2 is quite large, likely reflecting not only greenfield growth but also mergers, entry, and exit. For example, for the post-SOX SG\&A sample, the sales-weighted growth rate is $6.6 \%$. Using a weighted growth rate as a target is important because the value of the parameter $\xi$ directly affects the growth implications of our model. More broadly, having an accurate estimate of $\xi$ is important for our main results, so we target the moment $\mathbb{E}_{y} \Delta_{3} y$ exactly in the bisection procedure for $\xi$ described above in our discussion of the model solution.

To estimate the rate of earnings conversion to cash flows, we follow the accounting literature and estimate $\hat{p}_{s}$ from a regression of earnings, $\pi_{t}$, on past, future, and current cash flows, $d_{t}$, with all variables scaled by average total assets. Specifically, we estimate $\hat{p}_{s}$ as the average of $\beta_{t-1}$ and $\beta_{t+1}$ from the following regression:

$$
\pi_{t}=\alpha+\beta_{t-1} d_{t-1}+\beta_{t} d_{t}+\beta_{t+1} d_{t+1}+v_{t}
$$

which is similar but not identical to the specification in Dechow and Dichev (2002). Because cash collection and disbursement policies can be firm- and year-specific, we include firm and year fixed effects in this regression. For the post-SOX SG\&A sample, $\hat{p}_{s}$ equals $18 \%$, that is, $18 \%$ of earnings gets collected in cash in the preceding or following years.

We estimate the model's remaining parameters using a simulated minimum distance estimator, where we need to simulate because of the presence of the earnings reshuffling shock, $\zeta_{i t}^{s}$. The mechanics of the estimation are straightforward and by now familiar (Bazdresch, Kahn, and Whited 2018). For a given set of parameters, we solve the model and use the solution to generate simulated data, which is ten times the size of our data set (Michaelides and $\mathrm{Ng} 2000$ ). Next, we calculate a set of statistics, which are either moments or functions of moments. Based on the distance between model-generated statistics and their empirical counterparts, the values of the structural parameters are updated. To gauge this distance, 
we use the inverse covariance matrix of the empirical moments. To minimize the econometric objective function, we use a global stochastic optimization routine.

\subsection{Identification}

We have nine remaining model parameters to estimate: $p_{w}$, the relative price of intangible investment; $\gamma$, the elasticity of innovation to investment; $\rho_{y}$ and $\sigma_{y}$, the persistence and volatility of the fundamental shock; $\sigma_{\pi}$, the volatility of the non-fundamental shock to profits; $\kappa_{f}$ and $\kappa_{q}$, the fixed and quadratic costs of manipulation, conditional upon discovery; $\lambda$, the probability of manipulation discovery, and $\theta_{f}$, the manager's incentive to report earnings growth.

To identify these parameters, we use 21 moment conditions. The first seven of these moments do not rely on manipulation data. The first is the mean ratio of intangible investment to sales, given by $\mathbb{E}\left(p_{w} w / y\right)$. The next three moments are variances. The first of these is the variance of observed dividend growth, $\Delta d$, defined as $\Delta d=2\left(d-d_{-1}\right) /\left(d+d_{-1}\right)$. The next two variances are those of the growth rates of reported earnings, $\Delta \pi$, and intangible investment, $\Delta w$, which are defined similarly. The next three moments are covariances, in particular, the three possible covariances between $\Delta d, \Delta \pi$, and $\Delta w$.

The remaining 14 moments relate directly to manipulation and detection events. We include the probability of detection, $\mathbb{E}\left(I_{D}\right)$, in which the dummy variable, $I_{D}$, indicates the actual discovery of manipulation in a period. We also target the mean absolute ratio of manipulation to sales, conditional upon detection, $\mathbb{E}\left(|b / y| \mid I_{D}\right)$, as well as the variance and skewness of the same manipulation ratio conditional upon detection.

To allow for the possibility that misreporting firms behave differently from non-misreporting firms, we also duplicate the covariance matrix of dividend growth, $\Delta d$, earnings growth, $\Delta \pi$, and intangible investment growth, $\Delta w$, except that we condition upon detection. Finally, recall that the change in bias, $b-b_{-1}$, directly shifts today's earnings. As such, this change is observable in detection events, so we also include in our list of moments the covariance 
of the growth rate of today's earnings bias level, $\Delta\left(b-b_{-1}\right)$, with earnings, dividend, and investment growth, all conditional upon detection. For completeness, we also include the variance of $\Delta\left(b-b_{-1}\right)$.

While each of these moments is related to nearly all the parameters in the model, some moments have strong monotonic relationships with certain parameters and are thus particularly useful for identifying those parameters. To ascertain the strength of these relationships, we perform a battery of comparative statics exercises, which we then use to justify our moment choices.

We start with technological parameters. The first technological parameter is the price of intangible investment, $p_{w}$. This parameter determines the costliness of intangible investment in terms of the numeraire output and thus maps directly into the size of intangible investment $\mathbb{E}\left(p_{w} w / y\right)$. The second technological parameter is $\gamma$, which governs the returns to intangible investment in the innovation equation (2). Intuitively, when this parameter is higher, intangible investment responds more strongly to shocks, so a high level for $\gamma$ results in high covariances between intangible investment and indicators of fundamentals, in particular, dividends and earnings, both unconditionally and conditional upon detection. Naturally, if investment is more responsive, it also has a higher variance, so $\gamma$ also affects this moment.

Next, we consider the persistence of the fundamental shock, $\rho_{y}$. This parameter affects many different moments. In particular, $\rho_{y}$ maps negatively into the volatility of all growth rates in the model for the simple reason that a high slope coefficient in an $A R(1)$ process maps into a low growth rate variance. This negative relation holds for all the growth rate volatility moments, both unconditionally and conditional upon detection. A separate, less mechanical effect is also at work. Because higher fundamental persistence makes today's fundamental shock more informative for tomorrow, the covariance between the output shock and investment increases. This effect leads to a higher covariance between dividend and investment growth. Because accruals manipulation allows the manager to choose a more fundamentals-aligned investment level without sacrificing earnings, this last effect is more 
pronounced when manipulation is discovered.

Unlike the persistence parameter, $\rho_{y}$, the volatility of the fundamental shock, $\sigma_{y}$, is a neutral volatility shifter that primarily affects observable growth rate variances. Although $\sigma_{y}$ mechanically affects covariances, these effects are small relative to the effects on volatilities.

The identification of the volatility of our nonfundamental earnings shock, $\sigma_{\pi}$, operates somewhat differently. First, we have a strong, mechanical, positive link between this parameter and the variance of earnings, both unconditionally and conditional upon detection. However, the volatility of non-fundamental shocks also maps into the volatility of investment, as long as there is a motive for real manipulation, which in our model takes the form of pressure to deliver short-term earnings growth. Naturally, this mapping is weaker when punishment of accruals-based manipulation, embodied in $\kappa_{f}$ and $\kappa_{q}$ is present.

Next, we consider the identification of the manipulation cost parameters, $\kappa_{q}$ and $\kappa_{f}$, and the probability of detection, $\lambda$. Three moments jointly identify these three parameters: the incidence of detection, and the mean and variance of the absolute bias. First, we consider how these three moments are affected by the probability of detection, $\lambda$, which governs the likelihood of the discovery of manipulation, and which is a Poisson-style shock in the model. Mechanically, the observed likelihood of detection goes up, but because firms internalize the likelihood of discovery in their manipulation choices, the amount and variance of manipulation falls. Thus, this parameter affects all three identifying moments.

Second, the quadratic cost parameter, $\kappa_{q}$ only affects two of these three moments. Because this parameter determines the costliness of accruals manipulation on the intensive margin, the mean absolute ratio of manipulation to sales, conditional upon detection, decreases in $\kappa_{q}$, as does the variance of bias upon detection. However, because $\kappa_{q}$ does not affect the extensive margin of manipulation, the incidence of detection is left unaffected.

Third, the parameter, $\kappa_{f}$, again only affects two of these three moments. This parameter quantifies the fixed costs of manipulation, conditional upon detection of manipulation. As such, $\kappa_{f}$ determines the cost of accruals manipulation at the extensive margin. Mechanically, 
a higher fixed cost of manipulation discovery leads to a lower probability of manipulation and hence detection, so the probability of detection is lower. A second effect operates through increasing returns to manipulation, which naturally arises in the presence of a fixed cost. In this case, manipulation does not occur unless it is highly worth it, so a high fixed cost implies a higher average bias, $\mathbb{E}\left(|b / y| \mid I_{D}\right)$. While $\kappa_{f}$ affects the level of bias, the effect on bias variance is near zero.

The zero effects of two of these three parameters on two different moments imply a nondegenerate mapping between the three parameters, $\left(\lambda, \kappa_{q}, \kappa_{f}\right)$, and the three moments: the incidence of detection, and the mean and variance of the absolute bias. This identification is bolstered by several other moments. For example, the parameters, $\kappa_{f}$ and $\kappa_{q}$, have differential effects on the skewness of manipulation, conditional upon detection. If $\kappa_{q}$ were near zero and $\kappa_{f}$ were high, then the magnitude of the manipulation would have higher skewness, as the firm would optimally manipulate infrequently, but it would manipulate a great deal when it did. Conversely, if $\kappa_{q}$ were high and $\kappa_{f}$ were zero, the distribution of manipulation would be much more symmetric, so skewness should depend on the relative magnitudes of $\kappa_{q}$ and $\kappa_{f}$. Next, when $\kappa_{q}$ is higher, more manipulation occurs through investment, so the variance of investment growth increases, and the covariance between investment and dividend growth falls, as investment becomes a tool with which to respond to non-fundamental shocks. Finally, we include the covariance between investment growth and the growth in earnings bias, conditional on detection. This moment is a direct measure between the substitution between real and accruals manipulation. As such, it becomes sharply more negative as $\kappa_{q}$ rises. $^{7}$

The magnitude of managers' incentive to meet their lagged profit benchmark, $\theta_{f}$, is identified from the covariances between investment growth and both dividend and profit growth. The relation between these two moments and $\theta_{f}$ arises, because $\theta_{f}$ changes the manner in which R\&D investment relates to firm dividend and profit flows. When $\theta_{f}=0$ and

\footnotetext{
${ }^{7}$ For completeness, we also include the covariance with of earnings bias growth with the other model variables as overidentifying moments.
} 
managers face no manipulation incentives, persistent fundamental shocks $\nu_{y}$ tend to push dividend and profit flows in the same direction as investment. However, when managers face stronger incentives to beat earnings benchmarks with higher levels of $\theta_{f}$, then managers will sometimes cut their R\&D after unlucky shocks in order to maintain profit growth. The result is a lower, and in severe enough cases negative, covariance between investment growth and both dividend and profit growth. Naturally, because investment is used as a smoothing tool for profits, the volatility of investment growth also rises with higher $\theta_{f}$.

\subsection{Estimation results}

The results from our estimation using the SG\&A sample are in Table 3. For this estimation, we use data only from the post-SOX years so that we do not confront a model that contains one policy regime with data generated by two different policy regimes. In Panel A, we report the actual data moments, the model-simulated moments, and $t$-statistics for the null of the equality of each pair of moments. While all but five moment pairs are significantly different from one another, few are economically different from one another. This result stems from the high degree of over identification in our model: 21 moments and nine parameters. Nonetheless, three of the insignificantly different moment pairs are related directly to earnings manipulation: the incidence of detection, and the variance and skewness of absolute bias, given detection. The moments that exhibit the greatest differences in the model versus the data are all variances, with the model variances much smaller than the data variances. The one exception to this pattern is the variance of investment, which is well-matched. This result is to be expected, as the noise in growth rates in our real data exceeds the amount of variation that can be generated by our two model shocks. Finally, the model matches the signs of nearly all of the covariances, with the one exception related to the dividend covariances. However, dynamic models without explicit dividend smoothing motives are well known to struggle with dividend dynamics (Wu 2018). Overall, the fit of the model is remarkably good in those dimensions that are important for our policy experiments: investment and earnings 
manipulation.

Next, we turn to the parameter estimates, which are reported in Panel B. These parameters divide naturally into two groups, reflecting firm fundamentals on the one hand and income reporting or manager incentives on the other hand. Turning to the first group of parameter estimates, the implied fundamentals for firms are in line with many of the extant estimates in the literature. Intangible investment has a relative price of near one with $\hat{p}_{w} \approx 0.98$, reflecting a cost of intangible investment comparable to that of numeraire output. The persistence of productivity or profitability of $\hat{\rho} \approx 0.49$ lies below the level of the estimated persistence of productivity in all U.S. firms estimated by Winberry $(2016)(\approx 0.78)$ but near the level estimated by Castro, Clementi, and Lee $(2015)(\approx 0.45)$ in U.S. manufacturing. This result is to be expected because our model of growth at the firm level endogenizes a meaningful amount of persistence at firms through accumulation of the intangible asset rather than relying on the exogenous process for such persistence, as in a wide range of commonly used stationary models of firm dynamics. The total conditional volatility of shocks to firm profitability each year is $\sqrt{\hat{\sigma}_{y}^{2}+\hat{\sigma}_{\pi}^{2}} \approx 0.32$, which is comparable to the total volatility of shocks to U.S. public firms estimated by studies that omit a role for non-fundamental shocks such as Gourio and Rudanko (2014). Finally, the estimated elasticity of innovation to intangible investments $\hat{\gamma} \approx 0.7$ lies well below one, consistent with the evidence from patenting, firm growth, and R\&D in papers including Acemoglu, Akcigit, Bloom, and Kerr (2013). The parameters governing reporting and earnings growth incentives for the manager, $\kappa_{q}, \kappa_{f}$, and $\theta_{f}$ mostly relate to manager preferences and lack a direct empirical equivalent. One exception is the probability of detection, $\hat{\lambda} \approx 0.015$, which is somewhat lower than the estimates from a similar dynamic model in Zakolyukina (2018). Overall, the parameters in Table 3 are all precisely estimated and appear reasonable.

Table 4 contains the results from estimation the model using the R\&D sample. While the results are similar overall, the model fit is worse. For example, only three of the moment pairs are insignificantly different from each other, despite the smaller sample size. Moreover, 
the model falls far short in matching the mean ratio of investment to sales and the variance of absolute bias given detection, both of which are important moments to match given that our counterfactuals center around investment and bias. Accordingly, we conduct the rest of our analysis using the SG\&A sample.

Next, in Table 5, we present model estimations using two different definitions of restatements. The first is irregularity restatements, and the second is revenue recognition and irregularity restatements combined, where this second definition is the one we use in our main analysis. Our intent in this comparison is to isolate those restatements -irregularity restatements - that are more likely to be intentional. As seen in Panel A of Table 5, the fit of the model using each of these two restatement definitions is similar. As expected, the magnitudes of the moments involving restatements for the two definitions are different. In the case of more serious restatements, the incidence of detection is $31 \%$ lower, and the absolute size of bias, given detection, is $17 \%$ higher. Given these differences in the bias moments, the constellations of parameters from these two estimations are also different. In the case of the more serious restatements, the estimates of the non fundamental shock variance, $\sigma_{\pi}$, the incentive to beat last-period's earnings, $\theta_{f}$, and the fixed cost of manipulation, $\kappa_{f}$ are all higher than the corresponding estimates when we use the less serious restatements. This result can be reconciled with the incentives we model as follows. A higher shock variance, $\sigma_{\pi}$, and a higher threshold-beating incentive, $\theta_{f}$, give the manager more room and more incentive to use earnings manipulation, so we should expect to see larger absolute manipulation more often. At the same time, a higher fixed cost of manipulation, $\kappa_{f}$, lowers the incidence of manipulation, without having much effect on the average size of manipulation incidents. We conclude that using the more serious restatement definition results in parameter estimates that are consistent with more intentional manipulation. As such, this exercise serves as a useful external validation of the model.

In Table 6, we present the results from two estimations. The first estimation is our baseline estimation from Table 3, in which we use data in the post-SOX period. For the 
second estimation, we use data from the pre-SOX period. However, for this estimation, we assume that all parameters that are unrelated to detection and punishment are as estimated for the post-SOX period. Our intent is to estimate deep technological and utility parameters with the larger post-SOX sample, and then assume that these parameters are the same in the pre-SOX sample.

In Panel $\mathrm{A}$, we see that $t$-statistics on the moment conditions are smaller in the pre-SOX period, with the reason being the much smaller sample size. More important are the differences across the two subperiods in observable moments related to misreporting. Interestingly, while we see a slightly higher incidence of detection post-SOX, neither the size nor the variability of bias differs noticeably across the two subperiods. To understand how the model can reconcile these differences, we turn to the parameters in Panel B. Naturally, we see a probability of detection that is nearly twice as high in the post-SOX period. However, we also see a higher fixed cost of detection, $\kappa_{f}$. A large rise in the ex ante detection probability combined with the rise in the cost of the extensive margin of manipulation together result in a small rise in observed detection. Next, we see a drop in the quadratic cost of detection. While the fall in this parameter is large, the elasticity of this parameter with respect to mean absolute bias is

only approximately -0.2 , so the fall in the parameter from the post- to the pre-SOX period is associated with the observed small rise in mean absolute bias. In the end, estimating the model in these two subperiods helps us understand the small observed changes in the incidence and size of manipulation. We conclude that while SOX led to a sharp increase in the likelihood of detection, the endogenous response of managers to higher punishment led at the same time to fewer manipulation incidents.

\subsection{The dynamics of restatement and intangible investment}

As a final external validity check on the model, we examine the behavior of an important empirical pattern. To motivate this exercise, we recall that the model provides incentives for managers to shift reported profits upwards to beat earnings targets. While managers can 
achieve this goal with two tools, biased reporting or real investment cuts, each tool is costly on the margin. The direct implication within the model is that managers use both levers to manipulate their earnings upward in such periods, leading to a positive shift in bias as well as a lower level of intangible investment. Empirically, Figure 1 displays exactly this pattern.

But does the empirical result hold up when estimated with simulated model data? To answer this question, we run in simulated data the same panel regressions used to generate Figure 1, which are given by:

$$
X_{j t}=\sum_{k=-K}^{K} \beta_{k} \mathbb{I}(\text { Upward Bias Restated })_{j t+k}+\varepsilon_{j t} .
$$

To match our empirical approach in the construction of Figure $1, X_{j t}$ is either the R\&D to sales ratio in the model (left panel) or the bias to sales ratio (right panel). In Figure 3, we plot the coefficients, $\beta_{k}$, that trace out the within-firm idiosyncratic variation in intangible investment at horizons $k$ periods away from the restatement event. The red line on the left-hand side plots the resulting dynamics of $R \& D$ in the data, and we see a quick drop in R\&D of around $2.5 \%$ for the firm in periods in which upward bias is restated, labelled " 0. ." On the right-hand side, we see upward manipulation of reported earnings by a bit more than $35 \%$ on average.

The dynamic patterns in the data in Figure 1 were untargeted, and their model counterparts for investment in Figure 3 are not too far off in magnitude. The qualitative message in both cases is also clear. Managers cut their investment in periods in which they have upwardly misreported profits. Examination of each plot in Figure 1 and Figure 3 also reveals that the model and data dynamics match along another untargeted dimension, the transitory nature of the associated $R \& D$ declines. In the model, $R \& D$ rebounds quickly because of the short-lived nature of opportunities for manipulation. The transitory observed fluctuation in R\&D is not an extraneous feature of the model. Instead, mismatch between the short-term variation in incentives to manipulate long-term investment, on the one hand, and more persistent 
variation in incentives to invest, on the other hand, drive the efficiency loss for firms in a context with real investment manipulation.

\section{Counterfactuals}

Next, we quantify the tradeoff managers face between releasing more accurate income statements and choosing less efficient, more volatile investment paths. These calculations are based on a series of counterfactuals, which we report in Table 7 . We present four sets of results based on four different sets of model parameters. For each set of parameters, we consider three versions of the model: a model as estimated, a model with no reporting bias, and, for comparison, a value-maximizing firm. In Panel A, we present counterfactuals computed from the parameter estimates in Table 3, which contains an estimation based on the SG\&A sample. In the first column of Panel A, we see that managers optimally choose reporting bias equal to around $6.7 \%$ of sales, conditional upon restatement. In the second column, we examine model predictions when we set the costs of misreporting to very large numbers and thus shut it down. Naturally, under these conditions the manager releases income statements with no bias. This improved information disclosure results in a higher correlation between earnings and firm value. However, at the same time, investment variance rises, as managers without the ability to misreport their profits choose to manipulate through their investment alone. These distortions to the path of investment lead to a loss in the underlying or fundamental firm value of approximately 1\%. Finally, in the third column we consider an environment with no earnings manipulation incentives and value maximization. While not necessarily achievable in practice, this environment naturally results in no bias, a higher correlation between earnings and value, a much lower variance of investment growth, and a modest improvement in firm value.

In Panel B, we present the same set of results corresponding to the parameter estimates in Table 4, which contains an estimation based on the R\&D sample. Here, we find a much 
smaller drop in value when we make manipulation infinitely costly. This result stems from two sources. The first is the very small mean bias seen in the first column of panel B, and the second is the much lower value of the parameter that captures the incentive to beat earnings thresholds, $\theta_{f}$. If a small incentive to manipulate results in a low level of equilibrium manipulation, then removing this tool for distorting earnings has a small effect. Panel $\mathrm{C}$ contains counterfactuals corresponding to the parameters, reported in Table 5, from the estimation in which we use more serious restatements. Not surprisingly, the drop in firm value is approximately twice as large as the figure reported in Panel A. Finally, in Panel D, we report counterfactuals based on the parameters in Table 6 for the pre-SOX sample. Here, we find results quite similar to those in Panel A, which is not surprising, given the similarity of the pre- and post-SOX estimation in Table 6 .

The counterfactual cases considered in Table 7 are informative but extreme. To add texture to the results in Panel A of Table 7, we plot in Figure 4 the equilibrium trade-off between investment efficiency and bias in reporting as the cost of bias $\kappa_{q}$ varies more moderately. Specifically, each point on the curve reports value and bias moments from a counterfactual experiment. The baseline estimated parameterization of the model is represented by the black circle, and the curve is a polynomial interpolation of moments from a discrete set of counterfactual experiments in which we move $\kappa_{q}$ either up or down relative to the baseline, and all figures are expressed as percentages relative to this point. As the costs of manipulation decline, average bias increases (inversely) on the horizontal axis, but investment efficiency improves, as reflected in improved firm value, on the vertical axis. Starting from the empirical magnitude of bias in the data, a further reduction in bias can be achieved only through reductions in average firm value. Policymakers concerned with both the accuracy of income reporting and the real efficiency of firms must take the quantitative magnitude of this trade-off, which constrains their choices, into account when designing reporting regulation. 


\section{Conclusion}

We quantify the importance of managers' opportunistic distortion of information to the public as a force that improves the efficiency of their investment choices. While it is counterintuitive to imagine that less information could lead to better real outcomes, this seemingly counterintuitive connection makes sense in the context of widespread short-term incentives. On the one hand, many features of compensation contracts, such as performancebased equity compensation and bonus plans, give managers the incentive to manipulate earnings disclosures. On the other hand, disclosure or misreporting regulation does not erase these incentives, so when managers find it costly to misreport earnings, they substitute opportunistic cuts to investment, which can have adverse effects on shareholder value. Indeed, survey evidence suggests that managers facing pressures to report high earnings numbers appear to both misreport their earnings and distort long-term investments (Graham et al. 2005). If managers are willing to substitute between these two forms of manipulation, then reforms either to reporting regulations or executive compensation may face a crucial tradeoff between the accuracy of information reported by firms and the efficiency of long-term investment (Cohen et al. 2008).

However, given the scale of recent reforms to firm disclosure regulations, e.g. the SarbanesOxley Act in the United States, quantifying the extent of this trade-off seems crucial. Our vehicle for addressing this question is estimation of a dynamic model that incorporates all the ingredients necessary to generate the trade-off between misreporting and investment efficiency: an incentive structure with both short-term and long-term incentives, persistent investment opportunities that enhance firm growth, and punishment for misreporting. Because the extent of misreporting, the payoffs to long-term investments, and the counterfactual response of firms to various policy and compensation regimes are difficult to measure with reduced-form exercises, our question requires estimating a dynamic model.

Our results are interesting and potentially useful for informing the debate over information 
disclosure regulation. Our model estimates imply that when managers are caught misreporting and forced to restate, their reporting bias equals around $6.7 \%$ of sales. In the model, if we make the cost of misreporting high, it disappears, but then managers mistime investment so that it does not occur when investment opportunities are best. This suboptimal behavior cuts shareholder value by almost $1 \%$. The value loss from the existence of short-term incentives themselves is also meaningful, at about half a percent.

One ubiquitous drawback of our approach is the necessity of making model simplifications. For example, we only allow for one input into the production process, and the firm faces no financial frictions. We conjecture that advances in computing power will allow the specification of richer models to further our understanding of the little explored trade-offs between information manipulation, manager incentives, and the efficiency of the real economy. 


\section{References}

Acemoglu, Daron, Ufuk Akcigit, Nicholas Bloom, and William R. Kerr, 2013, Innovation, reallocation and growth, Working paper.

Aghion, Philippe, and Peter Howitt, 1992, A model of growth through creative destruction, Econometrica 60, 323-351.

Allen, Eric J., Chad R. Larson, and Richard G. Sloan, 2013, Accrual reversals, earnings and stock returns, Journal of Accounting and Economics 56, 113-129.

Armstrong, Christoper, Alan Jagolinzer, and David Larcker, 2010, Chief Executive Officer equity incentives and accounting irregularities, Journal of Accounting Research 48, 225-271.

Bazdresch, Santiago, R. Jay Kahn, and Toni M. Whited, 2018, Estimating and testing dynamic corporate finance models, Review of Financial Studies 31, 322-361.

Benmelech, Efraim, Eugene Kandel, and Pietro Veronesi, 2010, Stock-based compensation and CEO (dis)incentives, Quarterly Journal of Economics 125, 1769-1820.

Bettis, J. Carr, John Bizjak, Jeffrey L. Coles, and Swaminathan Kalpathy, 2010, Stock and option grants with performance-based vesting provisions, Review of Financial Studies 23, 3849-3888.

Bettis, J. Carr, John Bizjak, Jeffrey L. Coles, and Swaminathan Kalpathy, 2018, Performancevesting provisions in executive compensation, Journal of Accounting and Economics 66, $194-221$.

Burgstahler, David, and Ilia Dichev, 1997, Earnings management to avoid earnings decreases and losses, Journal of Accounting and Economics 24, 99-126.

Castro, Rui, Gian Luca Clementi, and Yoonsoo Lee, 2015, Cross-sectoral variation in the volatility of plant-level idiosyncratic shocks, Journal of Industrial Economics 63, 1-29.

Cheffers, Mark, Olga Usvyatsky, and John Pakaluk, 2014, Identifying accounting irregularities using Audit Analytics databases, Research report, Audit Analytics .

Choi, Stephen J., and Adam C. Pritchard, 2016, SEC investigations and securities class actions: An empirical comparison, Journal of Empirical Legal Studies 13, 27-49.

Coates, John C., and Suraj Srinivasan, 2014, SOX after ten years: A multidisciplinary review, Accounting Horizons 28, 627-671.

Cohen, Daniel A., Aiyesha Dey, and Thomas Z. Lys, 2008, Real and accrual-based earnings management in the pre- and post-Sarbanes-Oxley periods, The Accounting Review 83, $757-787$.

Cohen, Daniel A., and Paul Zarowin, 2010, Accrual-based and real earnings management activities around seasoned equity offerings, Journal of Accounting and Economics 50, 2-19. 
Cooper, Russell W., and John C. Haltiwanger, 2006, On the nature of capital adjustment costs, Review of Economic Studies 73, 611-633.

Davis, Steven J., and John C. Haltiwanger, 1992, Gross job creation, gross job destruction, and employment reallocation, Quarterly Journal of Economics 107, 819-863.

Dechow, Patricia M., and Ilia D. Dichev, 2002, The quality of accruals and earnings: The role of accrual estimation errors, The Accounting Review 77, 35-59.

Dechow, Patricia M., Weili Ge, Chad R. Larson, and Richard G. Sloan, 2011, Predicting material accounting misstatements, Contemporary Accounting Research 28, 17-82.

Dechow, Patricia M., Richard G. Sloan, and Amy P. Sweeney, 1995, Detecting earnings management, The Accounting Review 193-225.

DeGeorge, Francois, Jayendu Patel, and Richard Zeckhauser, 1999, Earnings management to exceed thresholds, Journal of Business 72, 1-33.

Dittmann, Ingolf, and Ernst Maug, 2007, Lower salaries and no options? On the optimal structure of executive pay, Journal of Finance 62, 303-343.

Edmans, Alex, Xavier Gabaix, and Dirk Jenter, 2017, Executive compensation: A survey of theory and evidence, in Benjamin E. Hermalin, and Michael S. Weisbach, eds., Handbook of corporate governance (Elsevier, Amsterdam).

Eisfeldt, Andrea L., and Dimitris Papanikolaou, 2013, Organization capital and the crosssection of expected returns, Journal of Finance 68, 1365-1406.

FASB, 1978, Objectives of financial reporting by business enterprises, Statement of Financial Accounting Concepts No. 1 .

Frydman, Carola, and Dirk Jenter, 2010, CEO compensation, Annual Review of Financial Economics 2, 75-102.

Gayle, George-Levi, Chen Li, and Robert A. Miller, 2016, Was Sarbanes-Oxley costly? Evidence from optimal contracting on CEO compensation, Technical Report 2015-017B, Working paper. Federal Reserve Bank of St. Louis, Research Division.

Gayle, George-Levi, and Robert A. Miller, 2015, Identifying and testing models of managerial compensation, Review of Economic Studies 82, 1074-1118.

Gerakos, Joseph J., Christopher D. Ittner, and David F. Larcker, 2007, The structure of performance-vested stock option grants, in Essays in accounting theory in honour of Joel S. Demski, 227-249 (Springer).

Glover, Brent, and Oliver Levine, 2017, Idiosyncratic risk and the manager, Journal of Financial Economics 126, 320-341.

Gourio, Francois, and Leena Rudanko, 2014, Customer capital, Review of Economic Studies $81,1102-1136$. 
Graham, John R., and Campbell R. Harvey, 2001, The theory and practice of corporate finance: Evidence from the field, Journal of Financial Economics 60, 187-243.

Graham, John R., Campbell R. Harvey, and Shiva Rajgopal, 2005, The economic implications of corporate financial reporting, Journal of Accounting and Economics 40, 3-73.

Hennes, Karen M., Andrew J. Leone, and Brian P. Miller, 2008, The importance of distinguishing errors from irregularities in restatement research: The case of restatements and CEO/CFO turnover, The Accounting Review 83, 1487-1519.

Hennessy, Christopher A., and Toni M. Whited, 2007, How costly is external financing? Evidence from a structural estimation, Journal of Finance 62, 1705-1745.

Hopenhayn, Hugo A., 1992, Entry, exit, and firm dynamics in long run equilibrium, Econometrica 60, 1127-1150.

Jones, Jennifer J., 1991, Earnings management during import relief investigations, Journal of Accounting Research 193-228.

Karpoff, Jonathan M., Allison Koester, D. Scott Lee, and Gerald S. Martin, 2017, Proxies and databases in financial misconduct research, The Accounting Review 92, 129-163.

Kothari, Sagar P., Andrew J. Leone, and Charles E. Wasley, 2005, Performance matched discretionary accrual measures, Journal of Accounting and Economics 39, 163-197.

Lambert, Richard, 2001, Contracting theory and accounting, Journal of Accounting and Economics 32, 3-87.

Leuz, Christian, and Peter D. Wysocki, 2016, The economics of disclosure and financial reporting regulation: Evidence and suggestions for future research, Journal of Accounting Research 54, 525-622.

Li, Chen, 2016, Mutual monitoring within top management teams: A structural modeling investigation, Manuscript, Baruch College.

Margiotta, Mary M., and Robert A. Miller, 2000, Managerial compensation and the cost of moral hazard, International Economic Review 41, 669-719.

Michaelides, Alexander, and Serena Ng, 2000, Estimating the rational expectations model of speculative storage: A Monte Carlo comparison of three simulation estimators, Journal of Econometrics 96, 231-266.

Nikolaev, Valeri V., 2016, Identifying accounting quality, Manuscript, University of Chicago.

Nikolov, Boris, and Toni M. Whited, 2014, Agency conflicts and cash: Estimates from a dynamic model, Journal of Finance 69, 1883-1921.

Palmrose, Zoe, Vernon Richardson, and Susan Scholz, 2004, Determinants of market reactions to restatement announcements, Journal of Accounting and Economics 37, 59-89. 
Romer, Paul M., 1990, Endogenous technological change, Journal of Political Economy 98, S71-S102.

Roychowdhury, Sugata, 2006, Earnings management through real activities manipulation, Journal of Accounting and Economics 42, 335-370.

Scholz, Susan, 2008, The changing nature and consequences of public company financial restatements 1997-2006, Research report, The Department of the Treasury .

Terry, Stephen J., 2015, The macro impact of short-termism, Manuscript, Boston University.

Whalen, Don, Olga Usvyatsky, and Dennis Tanona, 2016, 2015 financial restatements: A fifteen year comparison, Research report, Audit Analytics .

Winberry, Thomas, 2016, Lumpy investment, business cycles, and stimulus policy, Working paper.

Wu, Yufeng, 2018, What's behind smooth dividends? Evidence from structural estimation, Review of Financial Studies 31, 3979-4016.

Zakolyukina, Anastasia A., 2018, Measuring intentional GAAP violations: A structural approach, Journal of Accounting Research 56, 5-44.

Zang, Amy Y, 2011, Evidence on the trade-off between real activities manipulation and accrual-based earnings management, The Accounting Review 87, 675-703.

Zhu, John Y., 2013, Optimal contracts with shirking, Review of Economic Studies 80, 812-839. 
Figure 1: Dynamics around a restatement event

The figure plots the dynamics of intangible investment (left panel) and reporting bias (right panel) around firm restatement events in which book values were biased upwards. In particular, each solid line in the figure plots estimated coefficients $\beta_{k}, k=-2, \ldots 2$ from the panel regression $X_{j t}=\sum_{k=-2}^{2} \beta_{k} \mathbb{I}(\text { Upward bias restated })_{j t+k}+$ $I$ (Upward bias restated $)_{j t-3}+I$ (Upward bias restated $)_{j t+3}+f_{s}+g_{t}+\varepsilon_{j t}$. For firm $j$ at time $t$ in sector $s$, the variable $X$ is selling, general, and administrative expenditures or reported bias in book value, both relative to sales, $I$ (Upward bias restated $)_{j t-3}$ equals 1 for all years at least 3 years before the restatement event, and 0 otherwise, and $I$ (Upward bias restated $)_{j t+3}$ equals 1 for all years at least 3 years after the restatement event, and 0 otherwise. A full set of sector and time dummies together with indicators for public restatement of an upward bias in book values for firm $j$ at the horizon $k$ from year $t$ is included. We use $K=2$ for the figure estimates. The plotted error bands are $95 \%$ confidence intervals based on standard errors clustered by firm.
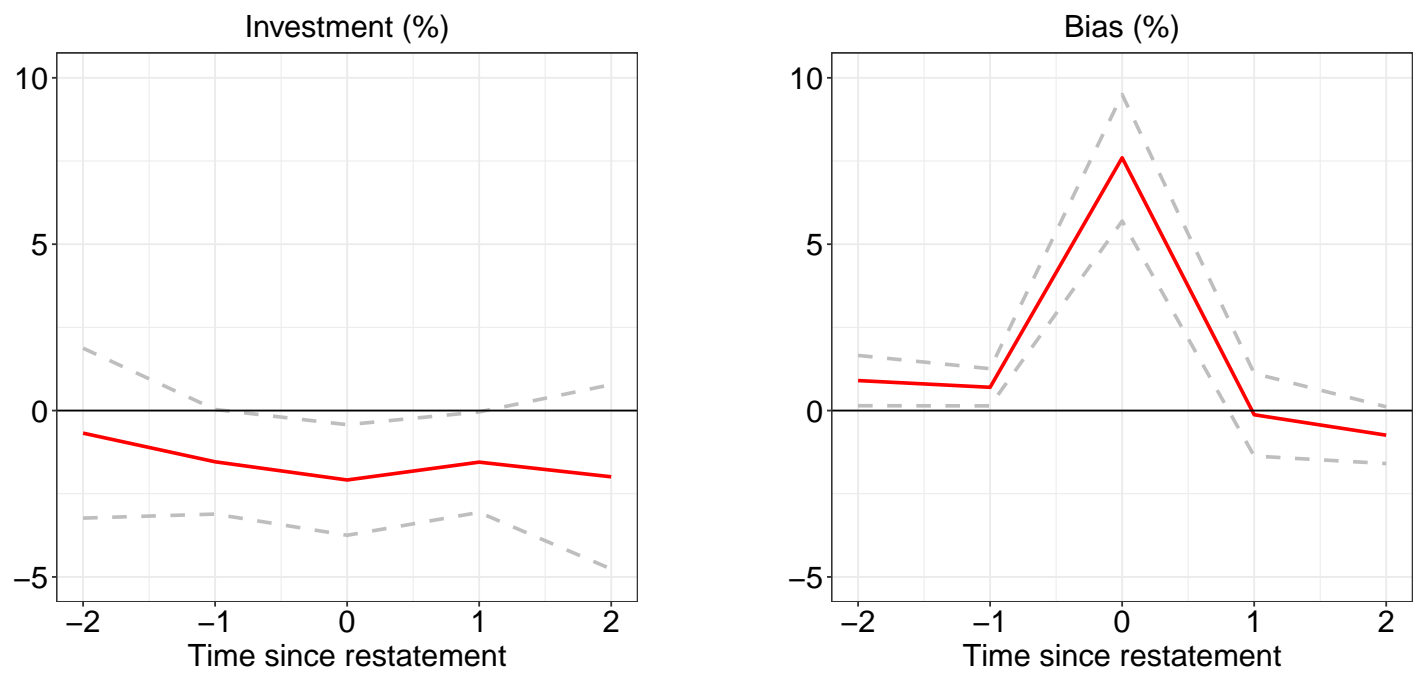
Figure 2: Investment and bias in the estimated model

Each panel of the figure plots a firm policy function - for their choice of investment (top row) or bias (bottom row) - in the estimated baseline model as a function of the fundamental shock $\nu_{y}$ (left column) and the non-fundamental profit shock $\nu_{\pi}$ (right column). The top row plots a firm's investment policy $w$ in percent deviations from the mean investment policy in the model. The bottom row plots a firm's bias policy $b$ as a percent of mean sales. The plotted policy functions are smoothed averages over the ergodic distribution of the model, conditioning on the indicated values of the fundamental and profit shocks.

(a) Output shock
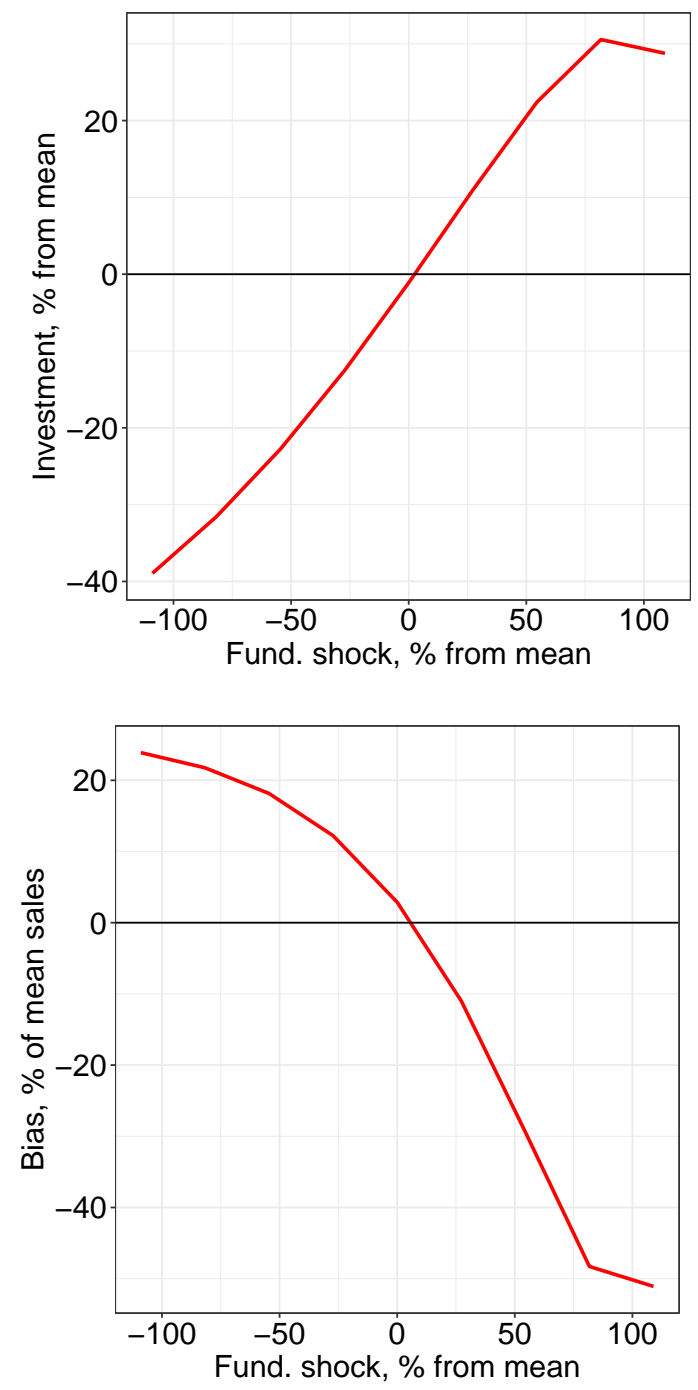

(b) Profit shock
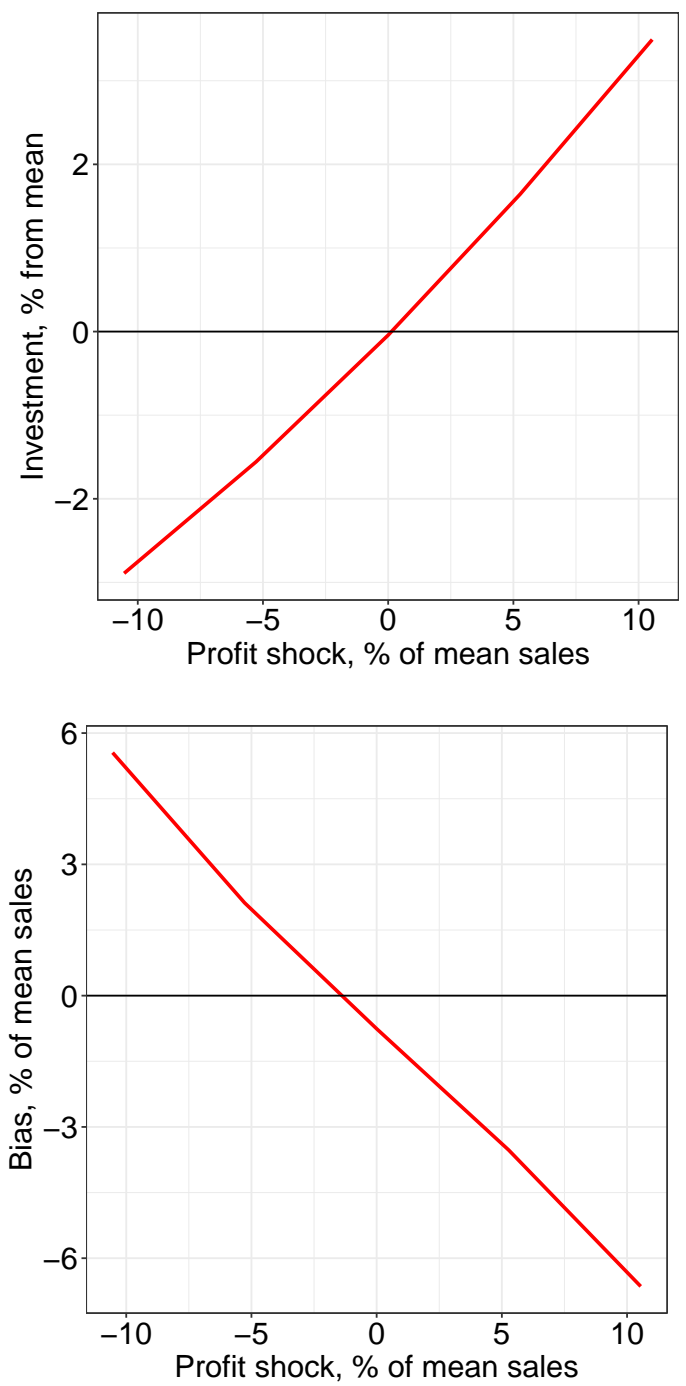
Figure 3: Dynamics around a restatement event: Simulated data

The figure plots the dynamics of intangible investment (left panel) and reporting bias (right panel) around firm restatement events in which book values were biased upwards for the simulated data. In particular, each solid line in the figure plots estimated coefficients $\beta_{k}, k=-2, \ldots 2$ from the panel regression $X_{j t}=$ $\sum_{k=-2}^{2} \beta_{k} \mathbb{I}$ (Upward bias restated) ${ }_{j t+k}+f_{j}+g_{t}+\varepsilon_{j t}$. For firm $j$ at time $t$, the variable $X$ is selling, general, and administrative expenditures or reported bias in book value, both relative to sales. A full set of firm and time dummies together with indicators for public restatement of an upward bias in book values for firm $j$ at the horizon $k$ from year $t$ is included. We use $K=2$ for the figure estimates. The plotted error bands are $95 \%$ confidence intervals based on standard errors clustered by firm.
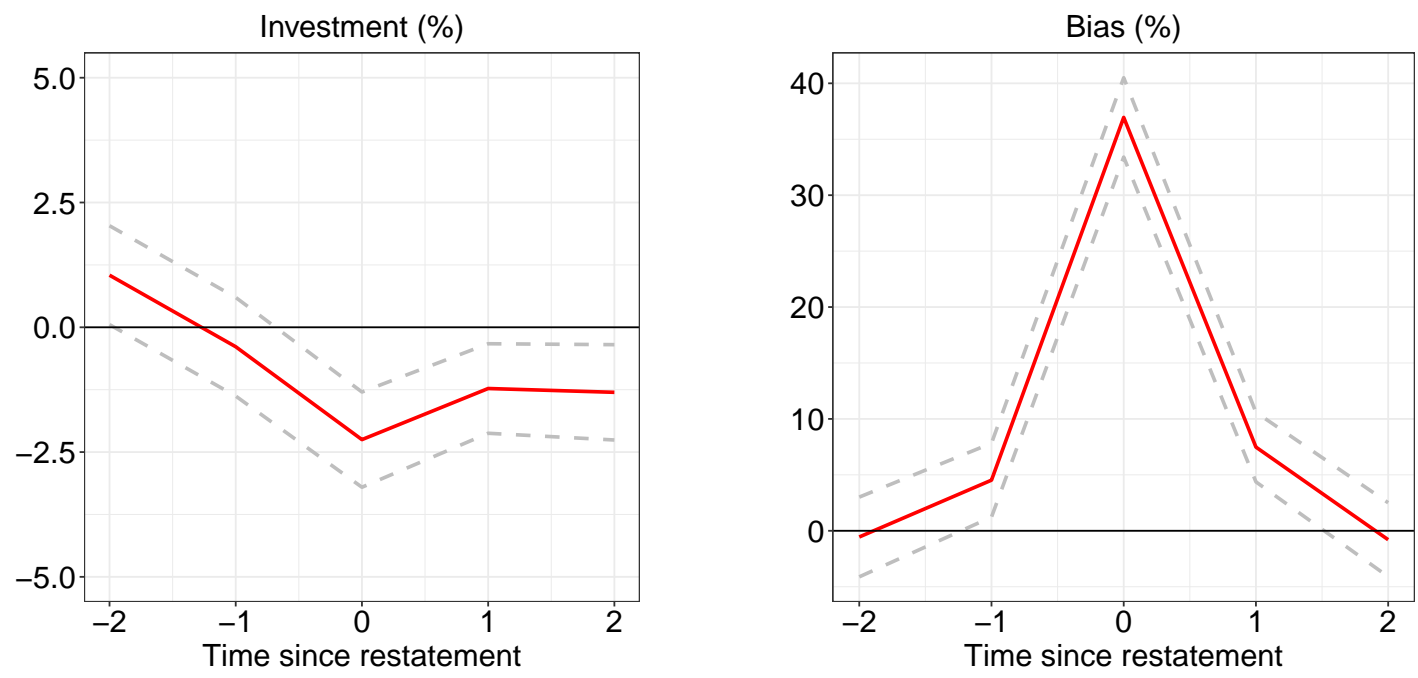


\section{Figure 4: Tradeoffs}

The figure plots the equilibrium average change in firm value (on the vertical axis) and average absolute bias relative to sales in restatements (on the horizontal axis). Each point on the curve reports moments from a counterfactual experiment, starting from the baseline estimated parameterization of the model and changing only the manager's cost of bias $\kappa_{q}$ either up or down. The curve is a polynomial interpolation of moments from a discrete set of counterfactual experiments. The empirical magnitude of bias is indicated by the black circular dot, and all value-change figures are expressed relative to this point.

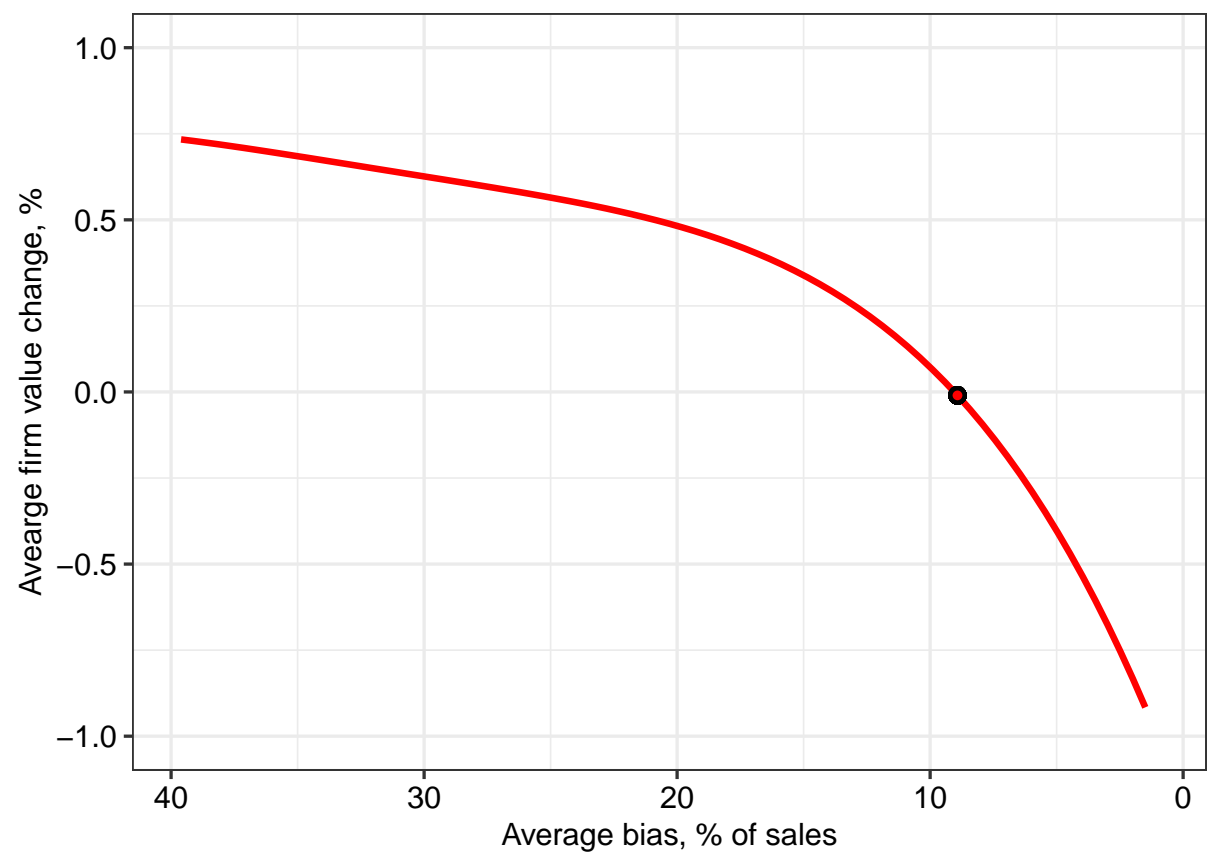




\section{Table 1: Data definitions}

This table presents definitions and data sources for variables used in estimation. Compustat data codes are in parentheses.

A. Firm-specific variables

$\theta_{d} \quad$ CEOs' stock holdings (excluding options exercisable within 60 days) as a fraction of total shares outstanding. Equilar.

y Sale revenues (SALE). Compustat.

$p_{w} w \quad$ Investment. For SG\&A sample, investment is XSGA; for R\&D sample, investment is XRD. Compustat.

$d \quad$ Free cash flow is cash from operations (OANCF) minus net capital expenditures (CAPX - SPPE). Compustat.

$\pi \quad$ Earnings is income before extraordinary items (IB). Compustat.

B. Restatement-specific variables

$I_{D} \quad$ The indicator variable for detection that equals 1 , when manipulation is detected and a firm restates its earnings. Audit Analytics advanced restatement feed.

$I_{R} \quad$ The indicator variable that equals 1 in the years in which retained earnings were corrected by a restatement. Audit Analytics advanced restatement feed.

$b \quad$ The bias in book value that equals the cumulative correction of net income. Audit Analytics advanced restatement feed. 


\section{Table 2: Descriptive statistics}

This table presents descriptive statistics for the variables used in estimation. The sample is based on Equilar, Audit Analytics advanced restatements, and Compustat. The sample covers the period from 1999 to 2015 at the annual frequency. Compustat data codes are in parentheses. Earnings is income before extraordinary items (IB). Free cash flow is cash from operations (OANCF) minus capital expenditures (CAPX - SPPE). $R \mathscr{E} D$ is R\&D expense (XRD) with missing values set to 0 . $S G E A$ is SG\&A expense (XSGA) with missing values set to 0 . Market value is the product of common shares outstanding (CSHO) and fiscal-year closing price (PRCC_F). Total assets is assets total (AT). Sales is sales revenue (SALE). Market-to-book is the sum of market value and total assets minus book value of equity divided by total assets. Fiscal-year return computed using fiscal-year closing stock prices. Ownership is the difference between shares owned (OWN_HOLDINGS) and options exercisable within 60 days (OWN_OPT_EX_60) divided by shares outstanding at fiscal year end (SHARES_OUTFFY). Bias in book value is the cumulative change in restated net income. Bias in earnings is the change in restated net income. We exclude financial firms and utilities. All variables are winsorized at the 1 st and 99 th percentiles.

A. SG\&A sample

\begin{tabular}{|c|c|c|c|c|c|c|}
\hline & Obs. & Mean & Std.Dev & p25 & p50 & $\mathrm{p} 75$ \\
\hline \multicolumn{7}{|c|}{ Revenue recognition errors and irregularities (Number of firms $=646$ ) } \\
\hline Bias in book value $(\$ \mathrm{mn})$ & 2,143 & 57.049 & 262.182 & 0.869 & 6.398 & 30.482 \\
\hline Bias in book value to sales & 2,143 & 0.067 & 0.237 & 0.002 & 0.011 & 0.055 \\
\hline Bias in earnings $(\$ \mathrm{mn})$ & 2,143 & 15.243 & 164.387 & 0.074 & 1.413 & 7.503 \\
\hline Bias in earnings to sales & 2,143 & 1.726 & 106.558 & 0.000 & 0.002 & 0.014 \\
\hline Annual bias in earnings growth & 2,143 & 0.293 & 1.525 & -1.070 & 0.310 & 2.000 \\
\hline \multicolumn{7}{|c|}{ Irregularities (Number of firms $=433$ ) } \\
\hline Bias in book value ( $\$ \mathrm{mn})$ & 1,531 & 76.330 & 307.387 & 1.615 & 10.626 & 41.727 \\
\hline Bias in book value to sales & 1,531 & 0.079 & 0.266 & 0.003 & 0.015 & 0.073 \\
\hline Bias in earnings $(\$ m n)$ & 1,531 & 20.171 & 193.576 & 0.171 & 1.891 & 10.128 \\
\hline Bias in earnings to sales & 1,531 & 2.404 & 126.075 & 0.000 & 0.003 & 0.016 \\
\hline Annual bias in earnings growth & 1,531 & 0.273 & 1.510 & -1.052 & 0.232 & 2.000 \\
\hline \multicolumn{7}{|c|}{ CEO equity holdings (Number of firms $=5,918$ ) } \\
\hline Ownership (\%) & 35,729 & 5.182 & 10.909 & 0.179 & 0.747 & 3.784 \\
\hline \multicolumn{7}{|c|}{ Firm characteristics (Number of firms $=5,918$ ) } \\
\hline Obs. & 51,535 & 13.441 & 5.353 & 9.000 & 15.000 & 19.000 \\
\hline Market value (\$bn) & 51,012 & 2.567 & 7.391 & 0.041 & 0.262 & 1.339 \\
\hline Total assets (\$bn) & 51,535 & 2.823 & 10.184 & 0.049 & 0.285 & 1.378 \\
\hline Sales (\$bn) & 51,535 & 2.226 & 6.317 & 0.047 & 0.275 & 1.287 \\
\hline Market-to-book & 51,012 & 2.397 & 4.672 & 1.086 & 1.486 & 2.310 \\
\hline Fiscal-year return & 50,910 & 0.178 & 0.837 & -0.282 & 0.023 & 0.370 \\
\hline Return on assets & 51,535 & -0.111 & 0.733 & -0.059 & 0.028 & 0.073 \\
\hline SG\&A to sales & 51,535 & 0.395 & 0.649 & 0.122 & 0.243 & 0.418 \\
\hline Annual free cash flow growth & 51,535 & 0.057 & 1.228 & -0.699 & 0.071 & 0.863 \\
\hline Annual earnings growth & 51,535 & 0.044 & 1.124 & -0.535 & 0.101 & 0.638 \\
\hline Annual SG\&A growth & 51,535 & 0.057 & 0.333 & -0.036 & 0.047 & 0.149 \\
\hline 3-year sales growth & 51,535 & 0.193 & 0.547 & -0.063 & 0.190 & 0.474 \\
\hline
\end{tabular}


Table 2: -Continued

B. R\&D sample

\begin{tabular}{|c|c|c|c|c|c|c|}
\hline & Obs. & Mean & Std.Dev & $\mathrm{p} 25$ & $\mathrm{p} 50$ & $\mathrm{p} 75$ \\
\hline \multicolumn{7}{|c|}{ Revenue recognition errors and irregularities (Number of firms $=397$ ) } \\
\hline Bias in book value $(\$ m n)$ & 1,320 & 61.264 & 249.101 & 0.900 & 7.732 & 35.077 \\
\hline Bias in book value to sales & 1,320 & 0.096 & 0.303 & 0.003 & 0.020 & 0.097 \\
\hline Bias in earnings $(\$ \mathrm{mn})$ & 1,320 & 16.863 & 124.681 & 0.100 & 1.535 & 8.014 \\
\hline Bias in earnings to sales & 1,320 & 2.797 & 135.781 & 0.000 & 0.004 & 0.023 \\
\hline Annual bias in earnings growth & 1,320 & 0.290 & 1.535 & -1.081 & 0.296 & 2.000 \\
\hline \multicolumn{7}{|c|}{ Irregularities (Number of firms $=280)$} \\
\hline Bias in book value ( $\$ \mathrm{mn})$ & 1,003 & 77.675 & 283.291 & 1.750 & 12.049 & 44.869 \\
\hline Bias in book value to sales & 1,003 & 0.109 & 0.333 & 0.003 & 0.030 & 0.129 \\
\hline Bias in earnings $(\$ \mathrm{mn})$ & 1,003 & 21.185 & 142.526 & 0.179 & 2.100 & 10.424 \\
\hline Bias in earnings to sales & 1,003 & 3.665 & 155.776 & 0.000 & 0.005 & 0.027 \\
\hline Annual bias in earnings growth & 1,003 & 0.250 & 1.515 & -1.071 & 0.199 & 2.000 \\
\hline \multicolumn{7}{|c|}{ CEO equity holdings (Number of firms $=3,542$ ) } \\
\hline Ownership (\%) & 21,565 & 4.222 & 9.506 & 0.146 & 0.624 & 2.780 \\
\hline \multicolumn{7}{|c|}{ Firm characteristics (Number of firms $=3,542$ ) } \\
\hline Obs. & 31,326 & 13.431 & 5.317 & 9.000 & 15.000 & 19.000 \\
\hline Market value (\$bn) & 31,145 & 2.706 & 7.980 & 0.037 & 0.220 & 1.210 \\
\hline Total assets (\$bn) & 31,326 & 2.735 & 10.993 & 0.032 & 0.176 & 0.974 \\
\hline Sales (\$bn) & 31,326 & 1.943 & 6.304 & 0.025 & 0.141 & 0.858 \\
\hline Market-to-book & 31,145 & 2.906 & 5.635 & 1.196 & 1.706 & 2.789 \\
\hline Fiscal-year return & 31,094 & 0.188 & 0.881 & -0.307 & 0.014 & 0.378 \\
\hline Return on assets & 31,326 & -0.189 & 0.885 & -0.143 & 0.018 & 0.071 \\
\hline R\&D to sales & 31,326 & 0.508 & 2.258 & 0.009 & 0.053 & 0.169 \\
\hline Annual free cash flow growth & 31,326 & 0.066 & 1.186 & -0.613 & 0.073 & 0.801 \\
\hline Annual earnings growth & 31,326 & 0.052 & 1.121 & -0.538 & 0.095 & 0.669 \\
\hline Annual R\&D growth & 31,326 & 0.033 & 0.470 & -0.076 & 0.010 & 0.171 \\
\hline 3 -year sales growth & 31,326 & 0.175 & 0.609 & -0.100 & 0.185 & 0.488 \\
\hline
\end{tabular}


Table 3: Baseline estimation results: SG\&A sample

The estimation is done with a simulated minimum distance estimator, which chooses structural model parameters by matching the moments from a simulated panel of firms to the corresponding moments from the data in the SG\&A sample. Panel A reports the simulated and actual moments and the t-statistics for the differences between the corresponding moments. Panel $\mathrm{B}$ reports the estimated structural parameters with standard errors in parentheses. $p_{w}$ is the price of intangible investment relative to output. $\rho_{y}$ is the serial correlation of the persistent productivity shock. $\sigma_{y}$ is the volatility of the persistent productivity shock. $\sigma_{\pi}$ is the volatility of the i.i.d. shock to earnings. $\kappa_{q}$ is the quadratic cost of manipulation. $\kappa_{f}$ is the fixed cost of manipulation. $\gamma$ is the curvature of the innovation production function. $\lambda$ is the probability of manipulation detection. $\theta_{f}$ is the manager incentive to beat lagged profits. The standard errors are double-clustered by firm and year in both panels.

A. Moments

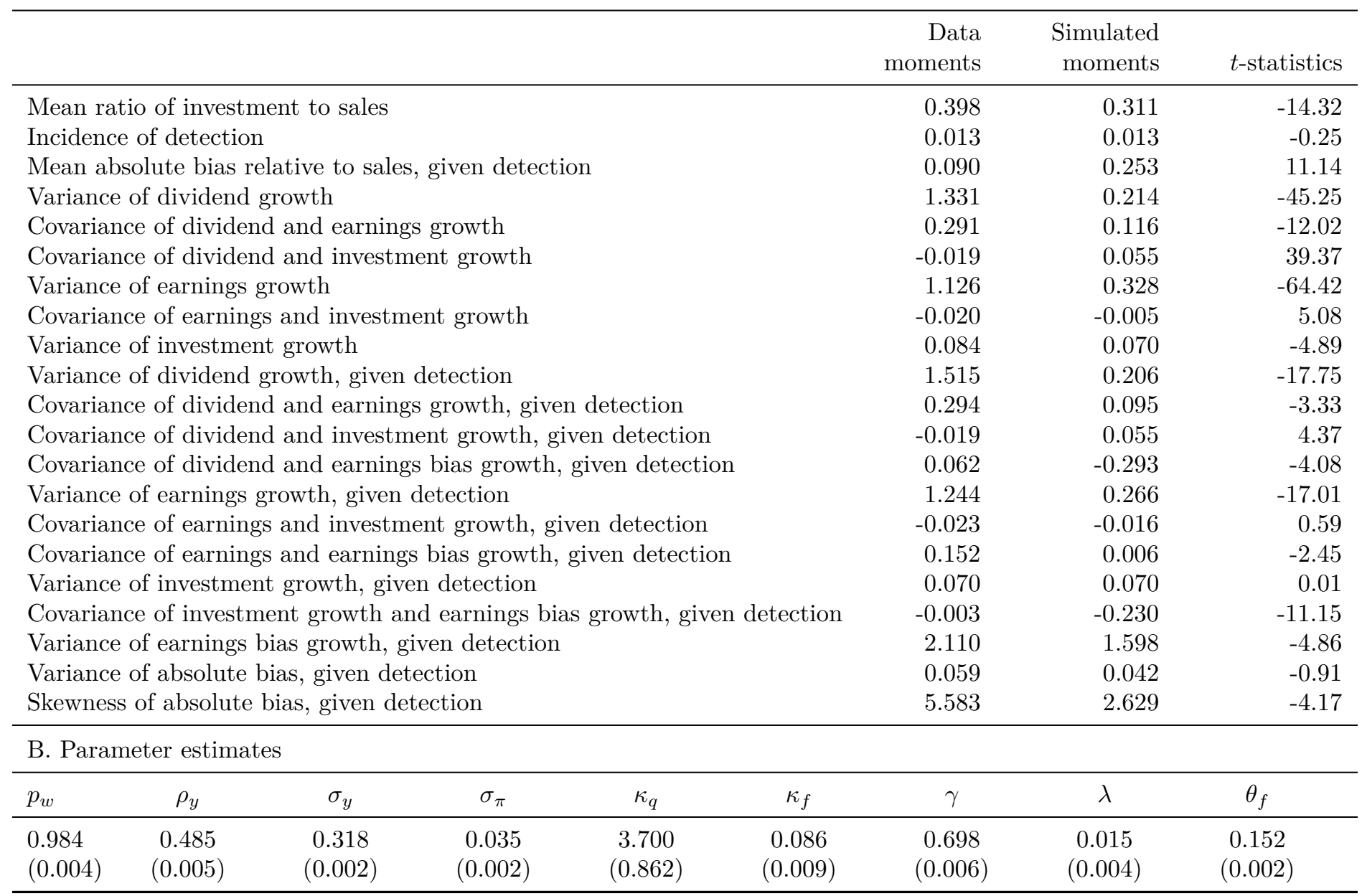


Table 4: Estimation results: R\&D sample

The estimation is done with a simulated minimum distance estimator, which chooses structural model parameters by matching the moments from a simulated panel of firms to the corresponding moments from the data in the R\&D sample. Panel A reports the simulated and actual moments and the t-statistics for the differences between the corresponding moments. Panel $\mathrm{B}$ reports the estimated structural parameters with standard errors in parentheses. $p_{w}$ is the price of intangible investment relative to output. $\rho_{y}$ is the serial correlation of the persistent productivity shock. $\sigma_{y}$ is the volatility of the persistent productivity shock. $\sigma_{\pi}$ is the volatility of the i.i.d. shock to earnings. $\kappa_{q}$ is the quadratic cost of manipulation. $\kappa_{f}$ is the fixed cost of manipulation. $\gamma$ is the curvature of the innovation production function. $\lambda$ is the probability of manipulation detection. $\theta_{f}$ is the manager incentive to beat lagged profits. The standard errors are double-clustered by firm and year in both panels.

A. Moments

\begin{tabular}{|c|c|c|c|c|c|c|c|c|}
\hline & & & & & & $\begin{array}{r}\text { Data } \\
\text { moments }\end{array}$ & $\begin{array}{r}\text { Simulated } \\
\text { moments }\end{array}$ & $t$-statistics \\
\hline \multicolumn{6}{|c|}{ Mean ratio of investment to sales } & 0.539 & 0.095 & -13.09 \\
\hline \multicolumn{6}{|c|}{ Incidence of detection } & 0.014 & 0.015 & 0.45 \\
\hline \multicolumn{6}{|c|}{ Mean absolute bias relative to sales, given detection } & 0.127 & 0.272 & 13.70 \\
\hline \multicolumn{6}{|c|}{ Variance of dividend growth } & 1.252 & 0.133 & -43.61 \\
\hline \multicolumn{6}{|c|}{ Covariance of dividend and earnings growth } & 0.343 & 0.059 & -19.76 \\
\hline \multicolumn{6}{|c|}{ Covariance of dividend and investment growth } & -0.042 & 0.029 & 17.48 \\
\hline \multicolumn{6}{|c|}{ Variance of earnings growth } & 1.121 & 0.234 & -104.02 \\
\hline \multicolumn{6}{|c|}{ Covariance of earnings and investment growth } & -0.055 & -0.012 & 11.57 \\
\hline \multicolumn{6}{|c|}{ Variance of investment growth } & 0.173 & 0.125 & -11.40 \\
\hline \multicolumn{6}{|c|}{ Variance of dividend growth, given detection } & 1.397 & 0.130 & -16.18 \\
\hline \multicolumn{6}{|c|}{ Covariance of dividend and earnings growth, given detection } & 0.380 & 0.036 & -6.05 \\
\hline \multicolumn{6}{|c|}{ Covariance of dividend and investment growth, given detection } & -0.049 & 0.025 & 3.12 \\
\hline \multicolumn{6}{|c|}{ Covariance of dividend and earnings bias growth, given detection } & 0.107 & -0.229 & -4.44 \\
\hline \multicolumn{6}{|c|}{ Variance of earnings growth, given detection } & 1.318 & 0.158 & -10.21 \\
\hline \multicolumn{6}{|c|}{ Covariance of earnings and investment growth, given detection } & -0.065 & -0.014 & 2.10 \\
\hline \multicolumn{6}{|c|}{ Covariance of earnings and earnings bias growth, given detection } & 0.168 & 0.000 & -1.29 \\
\hline \multicolumn{6}{|c|}{ Variance of investment growth, given detection } & 0.137 & 0.117 & -1.13 \\
\hline \multicolumn{6}{|c|}{ Covariance of investment growth and earnings bias growth, given detection } & 0.005 & -0.170 & -7.95 \\
\hline \multicolumn{6}{|c|}{ Variance of earnings bias growth, given detection } & 2.114 & 1.635 & -7.42 \\
\hline \multicolumn{6}{|c|}{ Variance of absolute bias, given detection } & 0.087 & 0.038 & -3.55 \\
\hline \multicolumn{6}{|c|}{ Skewness of absolute bias, given detection } & 4.513 & 1.946 & -8.11 \\
\hline \multicolumn{9}{|c|}{ B. Parameter estimates } \\
\hline$p_{w}$ & $\rho_{y}$ & $\sigma_{y}$ & $\sigma_{\pi}$ & $\kappa_{q}$ & $\kappa_{f}$ & $\gamma$ & $\lambda$ & $\theta_{f}$ \\
\hline $\begin{array}{l}1.140 \\
(0.008)\end{array}$ & $\begin{array}{c}0.453 \\
(0.007)\end{array}$ & $\begin{array}{c}0.279 \\
(0.001)\end{array}$ & $\begin{array}{c}0.031 \\
(0.002)\end{array}$ & $\begin{array}{c}2.097 \\
(0.187)\end{array}$ & $\begin{array}{c}0.156 \\
(0.076)\end{array}$ & $\begin{array}{c}0.787 \\
(0.007)\end{array}$ & $\begin{array}{c}0.017 \\
(0.002)\end{array}$ & $\begin{array}{c}0.105 \\
(0.021)\end{array}$ \\
\hline
\end{tabular}


च

票专

当

$\infty \doteq$

a क

웜

证

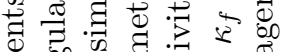

ปั

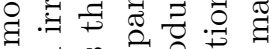

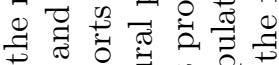

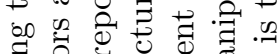

青它记

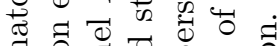

a . $.0 \%$

s.

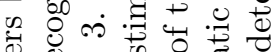

0 过

घे 0 चี

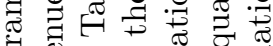

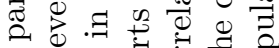

త

.

a

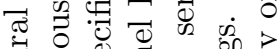

$\exists$.

प्र क्ष

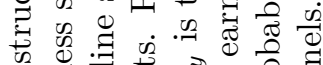

s.



政

द व 0 bo के की

궁

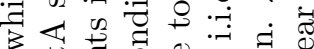

\&

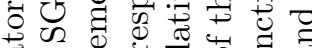

赵范范

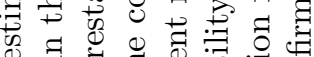

设

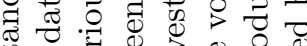

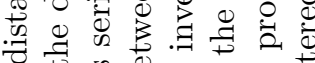

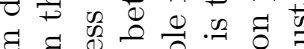

겸

I

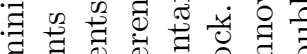

व

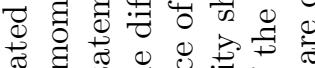

焉

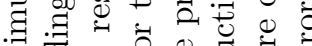

ज证

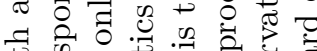

冓

उ.

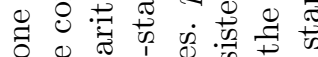

7 局

.

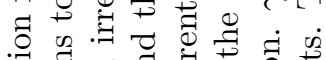

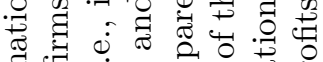

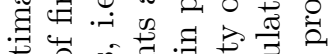

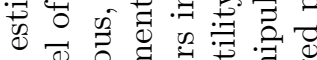

寻芯总

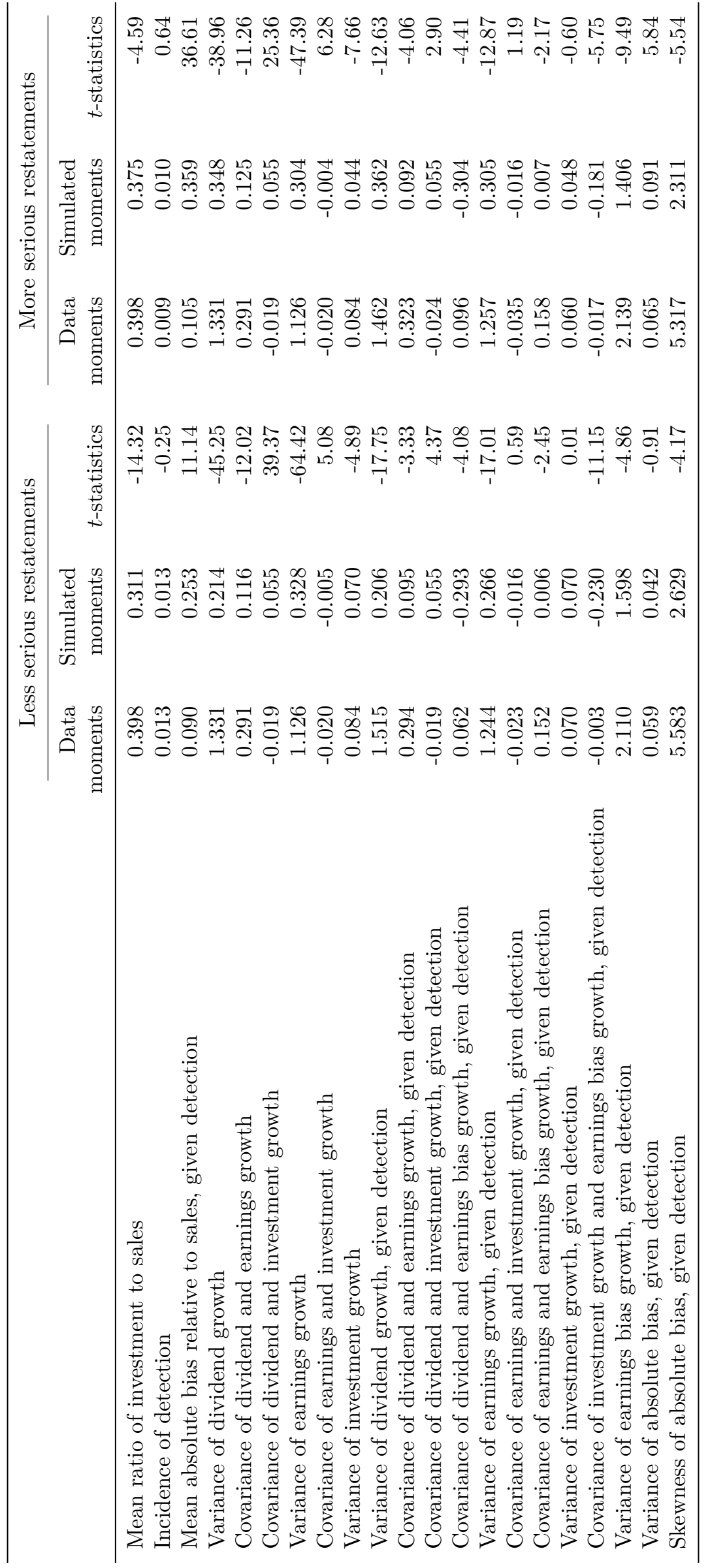

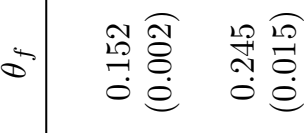

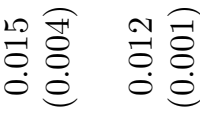

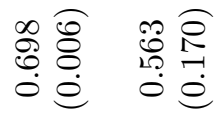

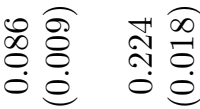

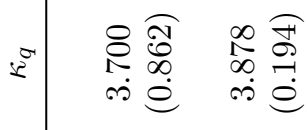

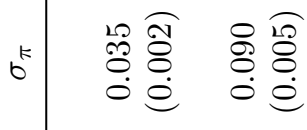

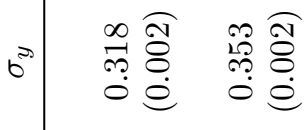

a

ص.

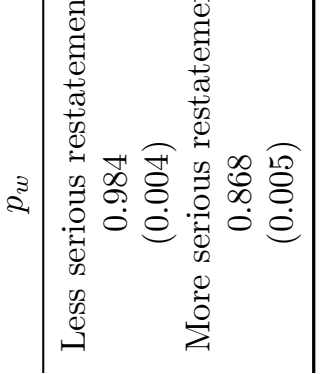




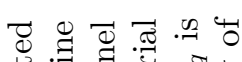

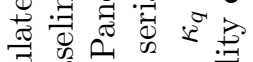

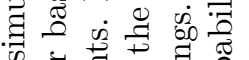

๘

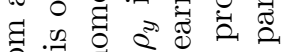

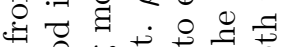

络.

층

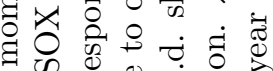

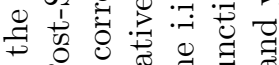

002 \&

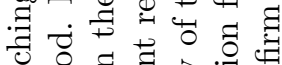

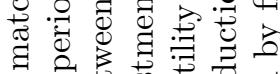

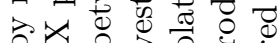

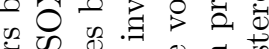

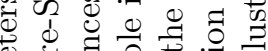

西

तु

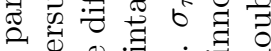

च ब

ए

त 100

O

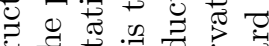

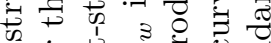

它

o

of

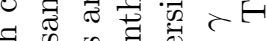

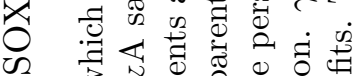

B 80

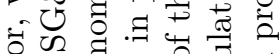

正

घ

渮

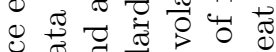

चี ซี चี

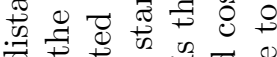

a

管

青落

自事过

व

व है

ఊ艹

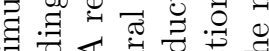

क

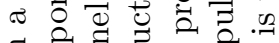

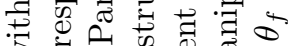

उ

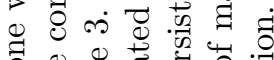

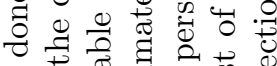

.

芩目

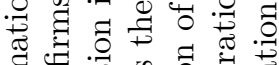

.

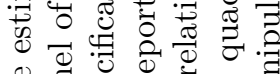

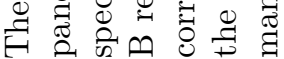

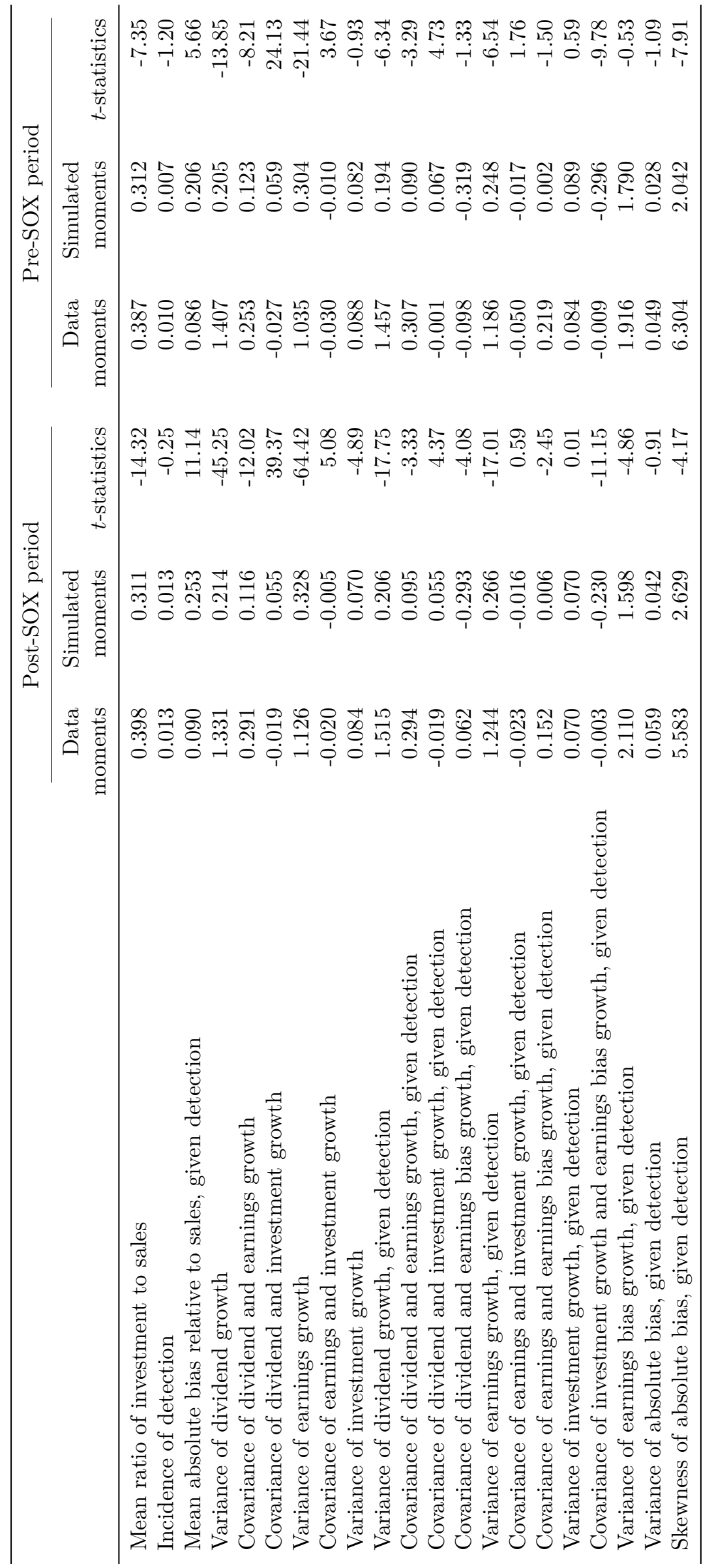


Table 7: Bias vs. value: counterfactual experiments

The table reports various outcomes computed under three alternative model parameterizations. The first column reports moments from the baseline model (with estimated parameters), the second column reports moments from a model with no accounting bias (identical to baseline with bias costs $\kappa_{f}, \kappa_{q}$ set to $\infty$ ), and the third column reports moments from a value maximizing model with no earnings growth incentives (identical to baseline with earnings incentive parameter $\theta_{f}=0$ ). The first row reports the mean bias relative to sales conditional upon detection. The second row reports the correlation between firm value and earnings. The third row reports the standard deviation of investment growth. The forth row reports the average change in fundamental firm value relative to the baseline model. All counterfactual moments are computed using the ergodic distribution of the respective models, with all units in percentage points except for correlations.

\begin{tabular}{|c|c|c|c|}
\hline & Estimated & $\begin{array}{c}\text { No bias } \\
\left(\kappa_{f}=\kappa_{q}=\infty\right)\end{array}$ & $\begin{array}{l}\text { Value maximizing } \\
\qquad\left(\theta_{f}=0\right)\end{array}$ \\
\hline \multicolumn{4}{|l|}{ A: SG\&A sample } \\
\hline Mean bias, $\%$ & 6.722 & 0.000 & 0.000 \\
\hline Corr. between firm value and earnings & 0.614 & 0.778 & 0.979 \\
\hline Std. dev of investment growth, $\%$ & 24.538 & 66.523 & 5.621 \\
\hline Firm value change from baseline, $\%$ & 0.000 & -1.005 & 0.309 \\
\hline \multicolumn{4}{|l|}{ B: R\&D sample } \\
\hline Mean bias, $\%$ & 0.630 & 0.000 & 0.000 \\
\hline Corr. between firm value and earnings & 0.621 & 0.937 & 0.984 \\
\hline Std. dev of investment growth, $\%$ & 31.678 & 54.478 & 6.834 \\
\hline Firm value change from baseline, $\%$ & 0.000 & -0.193 & 0.060 \\
\hline \multicolumn{4}{|c|}{ C: SG\&A sample with more serious restatements } \\
\hline Mean bias, $\%$ & 9.588 & 0.000 & 0.000 \\
\hline Corr. between firm value and earnings & 0.455 & 0.602 & 0.955 \\
\hline Std. dev of investment growth, $\%$ & 20.167 & 64.166 & 2.588 \\
\hline Firm value change from baseline, $\%$ & 0.000 & -2.000 & 0.550 \\
\hline \multicolumn{4}{|l|}{ D: Pre-SOX SG\&A sample } \\
\hline Mean bias, $\%$ & 5.918 & 0.000 & 0.000 \\
\hline Corr. between firm value and earnings & 0.641 & 0.778 & 0.979 \\
\hline Std. dev of investment growth, $\%$ & 27.894 & 66.523 & 5.621 \\
\hline Firm value change from baseline, $\%$ & 0.000 & -0.943 & 0.373 \\
\hline
\end{tabular}

